\title{
Entropy generation optimization and activation energy in nonlinear mixed convection flow of a tangent hyperbolic nanofluid
}

\author{
M. Ijaz Khan ${ }^{1, a}$, Tufail A. Khan ${ }^{2}$, Sumaira Qayyum ${ }^{1}$, T. Hayat ${ }^{1,2}$, Muhammad Imran Khan ${ }^{4, b}$, and A. Alsaedi ${ }^{3}$ \\ 1 Department of Mathematics, Quaid-I-Azam University 45320, Islamabad 44000, Pakistan \\ 2 Department of Basic Sciences, University of Engineering \& Technology, Peshawar, Pakistan \\ 3 Nonlinear Analysis and Applied Mathematics (NAAM) Research Group, Faculty of Science, King Abdulaziz University \\ P. O. Box 80207, Jeddah 21589, Saudi Arabia \\ ${ }^{4}$ Heriot-Watt University, Edinburgh Campus, Edinburgh EH14 4AS, UK
}

Received: 11 April 2018 / Revised: 3 June 2018

Published online: 21 August 2018

(C) The Author(s) 2018. This article is published with open access at Springerlink.com

\begin{abstract}
This study addresses the stagnation flow of a hyperbolic tangent nanofluid over a stretching sheet. Nonlinear convection, Brownian motion and thermophoresis are studied. In addition the nonlinear thermal radiation, dissipation and heat generation/absorption are taken into account. To characterize the effect of the Arrhenius activation energy, a binary chemical reaction is considered. The total entropy generation rate is calculated and discussed as per the criteria of the second law of thermodynamics. Convergent solutions for the resulting nonlinear systems are derived and the effects of embedded parameters of interest on velocity, concentration, temperature and entropy are examined. The skin friction coefficient and Nusselt and Sherwood numbers are numerically discussed.
\end{abstract}

\section{Introduction}

The first law of thermodynamics considers the quantity of energy, and states that it neither is created nor destroyed while the second law of thermodynamics concerns the quality of energy. However, the second law of thermodynamics is associated with energy dissipation in a process, entropy optimization and the loss of useful work. Various scientists and engineers carried out the analyses for entropy optimization using the second law of thermodynamics. The motivation for such analysis is based on the objectives to get optimum process parameters for various thermal devices. For instance, some studies analyze the entropy optimization in thermal devices in which nano-materials are utilized as coolant [1-5]. Ahmed et al. [6] studied the double diffusive slip flow of non-Newtonian materials and entropy generation over a nonlinear stretched surface. Entropy optimization and nanomaterial flow with micro-channel heat sink in a circular shaped minichannel and microchannel is discussed by Sohel et al. [7]. The fluid flow is discussed in the presence of alumina and copper nanoparticles with their volume fractions were varied from $2 \%$ to $6 \%$. The maximum decrease in entropy optimization was observed for $\mathrm{Cu}-\mathrm{H}_{2} \mathrm{O}$ nano-fluid. Hayat et al. [8] studied the entropy generation in the flow of viscous fluid having silver and copper nanoparticles. Govindaraju [9] examined the magnetohydrodynamic stretched nanoliquid flow of a viscous liquid with entropy generation. In another study, Sumaira et al. [10] investigated the nonlinear dissipative swirling flow and entropy optimization over a stretched surface. Similarly, the magnetohydrodynamic (MHD) flow of couple stress liquid between two rotating concentric cylinders with entropy generation was discussed by Nagaraju et al. [11]. Rashidi et al. [12] explored entropy generation in MHD time-dependent flow of viscous material in rotating disks. The authors used an artificial neural network via swarm algorithm optimization to predict the rate of entropy generation. Mahian et al. [13] explored entropy generation and nanomaterial flow between co-rotating cylinders. Gibanov et al. [14] studied entropy optimization and MHD forced convection flow in an open cavity subject to horizontal porous blocks. Khan et al. [15] discussed mixed convection nanomaterial stretched flow of a viscous liquid with entropy consideration.

\footnotetext{
a e-mail: mikhan@math.qau.edu.pk

b e-mail: mk42@hw.ac.uk (corresponding author)
} 


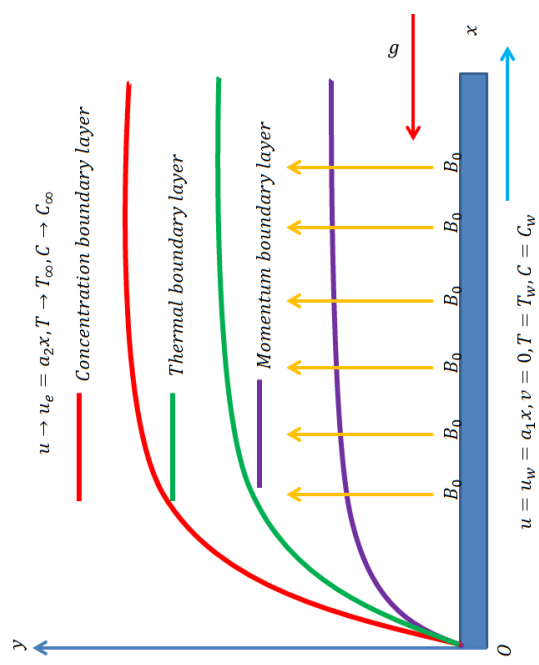

Fig. 1. Flow geometry.

Investigations involving binary chemical reaction with activation energy have gained continuous attention from engineers and scientists. Chemical species with activation energy are incorporated in different mechanical and industrial processes such as fibrous insulation, catalysis, air pollution and fog formation, etc. In practical life, such analysis is being used in the processes including production of ceramics, combustion and biochemical systems [16-20]. Hernandez et al. [21] analyzed the activation energy impact in viscous fluid flow. Kumar et al. [22] examined activation energy in Carreau liquid flow with binary chemical reaction and heat diffusion. Awad et al. [23] discussed heat and mass transfer in time-dependent rotating flow of viscous liquid with activation energy. Lu et al. [24] examined non-Fourier heat flux in single and multi-wall carbon nanotubes with activation energy. Ramzan et al. [25] examined radiative flow of non-Newtonian liquid with buoyancy and activation energy. Some further developments in this direction can be found by consulting refs. [26-30].

In this study, the MHD stagnation point flow of a hyperbolic tangent nanofluid subject to magnetic field, nonlinear thermal radiation, viscous dissipation and heat source/sink is studied. Binary chemical reaction associated with activation energy is considered. The mathematical modeling of a chemical reaction via activation energy has gained considerable attention of researchers. To the best of our knowledge, there is no systematic empirical research addressing the activation energy in the flow of a tangent hyperbolic nanofluid with entropy generation. Here we aim to provide such attempt. The governing nonlinear system is solved for series solutions by HAM [31-48]. Effectiveness of different flow variables on velocity, entropy generation, temperature, nanoparticle volume fraction is analyzed. Further coefficients of skin friction and Nusselt and Sherwood numbers are numerically examined. The obtained analysis is validated by comparison with those obtained by Waqas et al. [49] and Hayat et al. [50].

The rest of the paper is structured as follows. Section 2 discusses the formulation of the problem studied. Section 3 presents the physical parameters of interest. Section 4 interprets the homotopic solutions. Section 5 provides the mathematical modeling of entropy generation. Section 6 consists of convergence analysis. Section 7 describes the results discussion. Finally sect. 8 concludes this study.

\section{Formulation}

We considered a two-dimensional mixed convective stagnation point flow of a hyperbolic tangent fluid over a stretching surface. A constant magnetic field is implemented to the case-study fluid. Flow geometry and coordinates of the problem studied are presented in fig. 1.

We considered heat source/sink and viscous dissipation with total entropy generation. Additionally the characterizing features of chemical species of activation energy are accounted. The entropy optimization is obtained using the second law of thermodynamics. The governing equations for the flow analysis are $[49,50]$

$$
\begin{aligned}
\frac{\partial u}{\partial x}+\frac{\partial v}{\partial y}= & 0, \\
u \frac{\partial u}{\partial x}+v \frac{\partial u}{\partial y}= & u_{e} \frac{\mathrm{d} u_{e}}{\mathrm{~d} x}+\nu(1-s) \frac{\partial^{2} u}{\partial y^{2}}+\sqrt{2} \nu s \Gamma \frac{\partial u}{\partial y} \frac{\partial^{2} u}{\partial y^{2}}+\frac{\sigma B_{0}^{2}}{\rho_{f}}\left(u_{e}-u\right) \\
& +g\left[\lambda_{1}\left(T-T_{\infty}\right)+\lambda_{2}\left(T-T_{\infty}\right)^{2}\right]+g\left[\lambda_{3}\left(C-C_{\infty}\right)+\lambda_{4}\left(C-C_{\infty}\right)^{2}\right],
\end{aligned}
$$




$$
\begin{aligned}
u \frac{\partial T}{\partial x}+v \frac{\partial T}{\partial y}= & \frac{k}{\left(\rho c_{p}\right)_{f}} \frac{\partial^{2} T}{\partial y^{2}}+\tau\left\{D_{B} \frac{\partial C}{\partial y} \frac{\partial T}{\partial y}+\frac{D_{T}}{T_{\infty}}\left(\frac{\partial T}{\partial y}\right)^{2}\right\}+\frac{1}{\left(\rho c_{p}\right)_{f}} \frac{16 \sigma^{*}}{3 k^{*}}\left[3 T^{2}\left(\frac{\partial T}{\partial y}\right)^{2}+T^{3} \frac{\partial^{2} T}{\partial y^{2}}\right] \\
& +\frac{\sigma}{\left(\rho c_{p}\right)_{f}} B_{0}^{2} u^{2}+\frac{\mu}{\left(\rho c_{p}\right)_{f}}(1-s)\left(\frac{\partial u}{\partial y}\right)^{2}+\frac{\mu s \Gamma}{\left(\rho c_{p}\right)_{f} \sqrt{2}} \frac{\partial u}{\partial y}\left(\frac{\partial u}{\partial y}\right)^{2}+\frac{Q_{0}}{\left(\rho c_{p}\right)_{f}}\left(T-T_{\infty}\right), \\
u \frac{\partial C}{\partial x}+v \frac{\partial C}{\partial y}= & D_{B} \frac{\partial^{2} C}{\partial y^{2}}+\frac{D_{T}}{T_{\infty}} \frac{\partial^{2} T}{\partial y^{2}}-k_{r}^{2}\left(\frac{T}{T_{\infty}}\right)^{n} \exp \left[\frac{-E_{a}}{\kappa T}\right]\left(C-C_{\infty}\right),
\end{aligned}
$$

with

$$
\begin{aligned}
& u=u_{w}=a_{1} x, \quad v=0, \quad T=T_{w}, \quad C=C_{w}, \quad \text { at } y=0, \\
& u \rightarrow u_{e}=a_{2} x, \quad T \rightarrow T_{\infty}, \quad C \rightarrow C_{\infty}, \quad \text { as } y \rightarrow \infty .
\end{aligned}
$$

In above expressions $u, v$ and $x, y$ represent the velocity components and Cartesian coordinates, respectively. Similarly $s$ is the power law index, $\nu$ is the kinematic viscosity, $u_{w}$ is the stretching velocity, $\Gamma$ is the Williamson fluid parameter, $\sigma$ is the electrical conductivity, $g$ is the gravitational acceleration, $\lambda_{1}$ is the linear thermal expansion coefficient, $\lambda_{2}$ is the nonlinear thermal expansion coefficient, $\rho_{f}$ is the fluid density, $\lambda_{3}$ is the linear mass expansion coefficient, $\lambda_{4}$ is the nonlinear mass expansion coefficient, $u_{e}$ is the free stream velocity, $T$ is the temperature, $T_{\infty}$ is the ambient temperature, $k$ is the thermal conductivity, $B_{0}$ is the strength of magnetic field, $c_{p}$ is the specific heat, $k^{*}$ is the mean absorption coefficient, $\sigma^{*}$ is the Stefan-Boltzman constant, $a_{1}$ and $a_{2}$ are the stretching rates, $T_{w}$ is the wall temperature, $\tau\left(=\frac{\left(\rho c_{p}\right)_{s}}{\left(\rho c_{p}\right)_{f}}\right)$ indicates the ratio between effective nanoparticle material heat capacity and base fluid heat capacity, $\mu$ is the dynamic viscosity, $D_{B}$ is the Brownian diffusion coefficient, $C$ is the concentration, $D_{T}$ is the thermophoresis diffusion coefficient, $Q_{0}$ is the heat generation/absorption coefficient, $C_{\infty}$ is the ambient concentration, $k_{r}$ is the chemical reaction rate constant, $n$ is the fitted rate constant having values $-1<n<1, E_{a}$ activation energy and $\kappa=8.61 \times 10^{-5} \mathrm{eV} / \mathrm{K}$ is the Boltzmann constant.

Considering

$$
\xi=\sqrt{\frac{a}{\nu}} y, \quad u=a x f^{\prime}(\xi), \quad v=-\sqrt{a \nu} f(\xi), \quad \theta=\frac{T-T_{\infty}}{T_{w}-T_{\infty}}, \quad \phi=\frac{C-C_{\infty}}{C_{w}-C_{\infty}}
$$

the flow expressions become

$$
\begin{aligned}
& (1-s) f^{\prime \prime \prime}+s W e f^{\prime \prime} f^{\prime \prime \prime}-f^{\prime 2}+f f^{\prime \prime}+A^{2}-M\left(f^{\prime}-A\right)+\lambda \theta\left(1+\beta_{t} \theta\right)+\phi \lambda N^{*}\left(1+\beta_{c} \phi\right)=0 \\
& \frac{1}{\operatorname{Pr}} \theta^{\prime \prime}+\frac{R}{\operatorname{Pr}}\left(\theta\left(\theta_{w}-1\right)+1\right)^{2}\left(\theta^{\prime 2}\left(\theta_{w}-1\right)+\left(\theta\left(\theta_{w}-1\right)+1\right) \theta^{\prime \prime}\right) \\
& +f \theta^{\prime}+(1-s) E c f^{\prime \prime 2} \frac{s}{2} W e E c\left(f^{\prime \prime}\right)^{3}+N t \theta^{2}+N b \theta^{\prime} \phi^{\prime}+M E c f^{2}+\delta^{*} \theta=0 \\
& \phi^{\prime \prime}+\frac{N t}{N b} \theta^{\prime \prime}+S c f \phi^{\prime}-S c \sigma_{1}^{2}(1+\delta \theta)^{n} \exp \left[\frac{-v}{1+\delta \theta}\right] \phi=0, \\
& f(0)=0, \quad f^{\prime}(\infty) \rightarrow A, \quad f^{\prime}(0)=1, \quad \theta(0)=1, \quad \theta(\infty) \rightarrow 0, \quad \phi(0)=1, \quad \phi(\infty) \rightarrow 0
\end{aligned}
$$

Here $W e$ denotes the Weissenberg number, $A$ is the velocity ratio variable, $M$ is the Hartmann number, $\lambda$ is the mixed convection variable, $\beta_{t}$ is the nonlinear thermal mixed convection parameter, $N^{*}$ is the ratio of concentration to thermal buoyancy forces, $\beta_{c}$ is the nonlinear mixed convection variable for concentration, $\operatorname{Pr}$ is the Prandtl number, $\theta_{w}$ is the temperature ratio parameter, $R$ is the radiation parameter, $E c$ is the Eckert number, $\left(G r_{x}\right)$ and $\left(G r_{x}^{*}\right)$ are the Grashof number for temperature and concentration, respectively, $N t$ is the thermophoresis variable, $S c$ is the Schmidt number, $\mathrm{Nb}$ is the Brownian motion parameter, $\delta^{*}$ is the heat generation/absorption variable, $\sigma_{1}$ is the chemical reaction variable, $\delta$ is the temperature relative parameter and $v$ is the activation energy variable. 
The above dimensionless variables are defined as

$$
\begin{aligned}
W e & =\frac{a^{2 / 3} \sqrt{2} x \Gamma}{\sqrt{\nu}}, \quad A=\frac{a_{2}}{a_{1}}, \quad M=\frac{\sigma B_{0}^{2}}{\rho a}, \quad \lambda=\frac{G r_{x}}{\operatorname{Re}_{x}^{2}}, \quad \beta_{t}=\frac{\lambda_{2}\left(T_{w}-T_{\infty}\right)}{\lambda_{1}}, \quad N^{*}=\frac{G r_{x}^{*}}{G r_{x}}=\frac{\lambda_{3}\left(C_{w}-C_{\infty}\right)}{\lambda_{1}\left(T_{w}-T_{\infty}\right)}, \\
\beta_{c} & =\frac{\lambda_{4}\left(C_{w}-C_{\infty}\right)}{\lambda_{3}}, \quad \operatorname{Pr}=\frac{\rho c_{p} \nu}{k}, \quad R=\frac{16 \sigma^{*} T_{\infty}^{3}}{3 k k^{*}}, \quad \theta_{w}=\frac{T_{w}}{T_{\infty}}, \quad E c=\frac{a^{2} x^{2}}{c_{p}\left(T_{w}-T_{\infty}\right)}, \\
G r_{x} & =\frac{g \lambda_{1}\left(T_{w}-T_{\infty}\right) x^{3}}{\nu^{2}}, \quad G r_{x}^{*}=\frac{g \lambda_{3}\left(C_{w}-C_{\infty}\right) x^{3}}{\nu^{2}}, \quad N t=\frac{\left(\rho c_{p}\right)_{s} D_{T}\left(T_{w}-T_{\infty}\right)}{\left(\rho c_{p}\right)_{f} T_{\infty} \nu}, \quad S c=\frac{\nu}{D_{B}}, \\
N b & =\frac{\left(\rho c_{p}\right)_{s} D_{T}\left(C_{w}-C_{\infty}\right)}{\left(\rho c_{p}\right)_{f} \nu}, \quad \delta^{*}=\frac{Q_{0}}{a\left(\rho c_{p}\right)_{f}}, \quad \sigma_{1}=\frac{k_{r}^{2}}{a}, \quad \delta=\frac{T_{w}-T_{\infty}}{T_{\infty}}, \quad v=\frac{E_{a}}{\kappa T_{\infty}} .
\end{aligned}
$$

\section{Physical quantities}

\subsection{Coefficient of skin friction}

We have

$$
C_{f x}=\frac{2 \tau_{w}}{\rho u_{w}^{2}}
$$

where the wall shear stress $\tau_{w}$ is

$$
\tau_{w}=\left.\mu(1-s) \frac{\partial u}{\partial y}\right|_{y=0}+\left.\mu \frac{s \Gamma}{\sqrt{2}}\left(\frac{\partial u}{\partial y}\right)^{3}\right|_{y=0}
$$

Putting eq. (13) in eq. (12), one has

$$
\frac{1}{2} C_{f} \operatorname{Re}^{\frac{1}{2}}=(1-s) f^{\prime \prime}(0)+\frac{s W e}{2}\left(f^{\prime \prime}(0)\right)^{2} .
$$

\subsection{Heat transfer rate (Nusselt number)}

We have

$$
N u_{x}=\frac{x q_{w}}{k\left(T_{w}-T_{\infty}\right)},
$$

where $q_{w}$ represents the wall heat flux. Mathematically, one has

$$
q_{w}=-\left.k \frac{\partial T}{\partial y}\right|_{y=0}+\left(q_{r}\right)_{w} .
$$

Invoking eq. (16) in eq. (15), we have

$$
N u_{x} \operatorname{Re}^{-\frac{1}{2}}=\left[1+R \theta_{w}^{3}\right] \theta^{\prime}(0)
$$

\subsection{Sherwood number}

Mathematically,

$$
S h_{x}=\frac{x J_{w}}{D_{B}\left(C_{w}-C_{\infty}\right)},
$$

where $J_{w}$ indicates the wall mass flux and is defined as

$$
q_{m}=-\left.D_{B}\left(\frac{\partial C}{\partial y}\right)\right|_{y=0}
$$

From eqs. (19) and (18), we get the following form:

$$
S h_{x} \operatorname{Re}_{x}^{-0.5}=-\phi^{\prime}(0),
$$

where $C_{f x}$ denotes skin friction, $\operatorname{Re}_{x}\left(=\frac{a x^{2}}{\nu}\right)$ the local Reynolds number, $N u_{x}$ the Nusselt number and $S h_{x}$ the Sherwood number. 


\section{Homotopic solutions}

We write

$$
\begin{aligned}
& f_{0}(\xi)=1-\exp (-\xi), \quad \theta_{0}(\xi)=\exp (-\xi), \quad \phi_{0}(\xi)=\exp (-\xi), \\
& f_{0}(\xi)=1-\exp (-\xi), \quad \theta_{0}(\xi)=\exp (-\xi), \quad \phi_{0}(\xi)=\exp (-\xi), \\
& \mathbf{L}_{f}=f^{\prime \prime \prime}-f^{\prime}, \quad \mathbf{L}_{\theta}=\theta^{\prime \prime}-\theta, \quad \mathbf{L}_{\phi}=\phi^{\prime \prime}-\phi,
\end{aligned}
$$

with

$$
\mathbf{L}_{f}\left[c_{1}+c_{2} e^{\xi}+c_{3} e^{-\xi}\right]=0, \quad \mathbf{L}_{\theta}\left[c_{4} e^{\xi}+c_{5} e^{-\xi}\right]=0, \quad \mathbf{L}_{\phi}\left[c_{6} e^{\xi}+c_{7} e^{-\xi}\right]=0
$$

in which $c_{i}(i=1-7)$ represent arbitrary constants.

\section{Entropy modeling}

For the tangent hyperbolic fluid we mentioned

$$
\begin{aligned}
S_{G}= & \underbrace{\frac{k}{T_{\infty}^{2}}\left[1+\frac{16 \sigma^{*} T^{3}}{3 k k^{*}}\right]\left(\frac{\partial T}{\partial y}\right)^{2}}_{\text {Thermal irreversibility }}+\underbrace{\frac{\mu}{T_{\infty}} \Phi}_{\text {Fluid friction irreversibility }}+\underbrace{\frac{\sigma}{\hat{T}_{\infty} B_{0}^{2} u^{2}}}_{\text {Joule dissipation irreversibility }} \\
& +\underbrace{\frac{R D}{C_{\infty}}\left(\frac{\partial C}{\partial y}\right)^{2}+\frac{R D}{T_{\infty}}\left(\frac{\partial T}{\partial y} \frac{\partial C}{\partial y}\right)}_{\text {Concentration irreversibility }}
\end{aligned}
$$

where

$$
\Phi=(1-s)\left(\frac{\partial u}{\partial y}\right)^{2}+\frac{s \Gamma}{\sqrt{2}}\left(\frac{\partial u}{\partial y}\right)\left(\frac{\partial u}{\partial y}\right)^{2}
$$

Using the above expressions one can express that

$$
\begin{aligned}
S_{G}= & \underbrace{\frac{k}{T_{\infty}^{2}}\left[1+\frac{16 \sigma^{*} T^{3}}{3 k k^{*}}\right]\left(\frac{\partial T}{\partial y}\right)^{2}}_{\text {Thermal irreversibility }}+\underbrace{\frac{\mu}{T_{\infty}}\left[(1-s)\left(\frac{\partial u}{\partial y}\right)^{2}+\frac{s \Gamma}{\sqrt{2}}\left(\frac{\partial u}{\partial y}\right)\left(\frac{\partial u}{\partial y}\right)^{2}\right]}_{\text {Fluid friction irreversibility }}+\underbrace{\frac{\sigma}{T_{\infty}} B_{0}^{2}\left(u^{2}\right)}_{\text {Joule dissipation irreversibility }} \\
& +\underbrace{\frac{R D}{C_{\infty}}\left(\frac{\partial C}{\partial y}\right)^{2}+\frac{R D}{T_{\infty}}\left(\frac{\partial T}{\partial y} \frac{\partial C}{\partial y}\right)}_{\text {Concentration irreversibility }}
\end{aligned}
$$

In eq. (27), the first, second, third and fourth terms represent the thermal irreversibility, viscous dissipation, Joule heating irreversibility and concentration irreversibility, respectively.

\subsection{Entropy generation number}

The volumetric entropy generation is

$$
N_{G}=\left[1+R\left(\theta\left(\theta_{w}-1\right)+1\right)^{3}\right] \theta^{\prime 2} \alpha_{1}+B r(1-s) f^{\prime \prime 2}+B r \frac{W e}{2}\left(f^{\prime \prime}\right)^{3}+M B r f^{\prime 2}+L \frac{\alpha_{2}}{\alpha_{1}} \phi^{\prime 2}+L \theta^{\prime} \phi^{\prime}
$$

in which $\alpha_{1}\left(=\frac{T_{w}-T_{\infty}}{T_{\infty}}=\frac{\Delta T}{T_{\infty}}\right)$ highlights the temperature difference parameter, $B r\left(=\frac{\mu a^{2} x^{2}}{k \Delta T}\right)$ the Brinkman number, $\alpha_{2}\left(=\frac{C_{w}-C_{\infty}}{C_{\infty}}=\frac{\Delta C}{C_{\infty}}\right)$ the concentration difference variable, $L\left(=\frac{R D\left(C_{w}-C_{\infty}\right)}{k}\right)$ the diffusion variable and $N_{G}\left(=\frac{T_{\infty} S_{G} \nu}{a k \Delta T}\right)$ the local entropy generation. 
Table 1. HAM convergence solutions for $E c=\sigma_{1}=0.1, \theta_{w}=1.1, M=0.5, s=0.1=n, N t=N^{*}=N b=S c=0.01$, $\delta^{*}=R=0.2, \lambda=\beta_{t}=\beta_{c}=W e=\delta=A=0.1$ and $\operatorname{Pr}=2$.

\begin{tabular}{|c|c|c|c|}
\hline Order of approximation & $-f^{\prime \prime}(0)$ & $-\theta^{\prime}(0)$ & $-\phi^{\prime}(0)$ \\
\hline 1 & 1.1746 & 0.78438 & 0.99849 \\
\hline 8 & 1.2398 & 0.62055 & 0.99634 \\
\hline 17 & 1.2398 & 0.62101 & 0.99488 \\
\hline 24 & 1.2398 & 0.62101 & 0.99401 \\
\hline 30 & 1.2398 & 0.62101 & 0.99401 \\
\hline 40 & 1.2398 & 0.62101 & 0.99401 \\
\hline 50 & 1.2398 & 0.62101 & 0.99401 \\
\hline
\end{tabular}

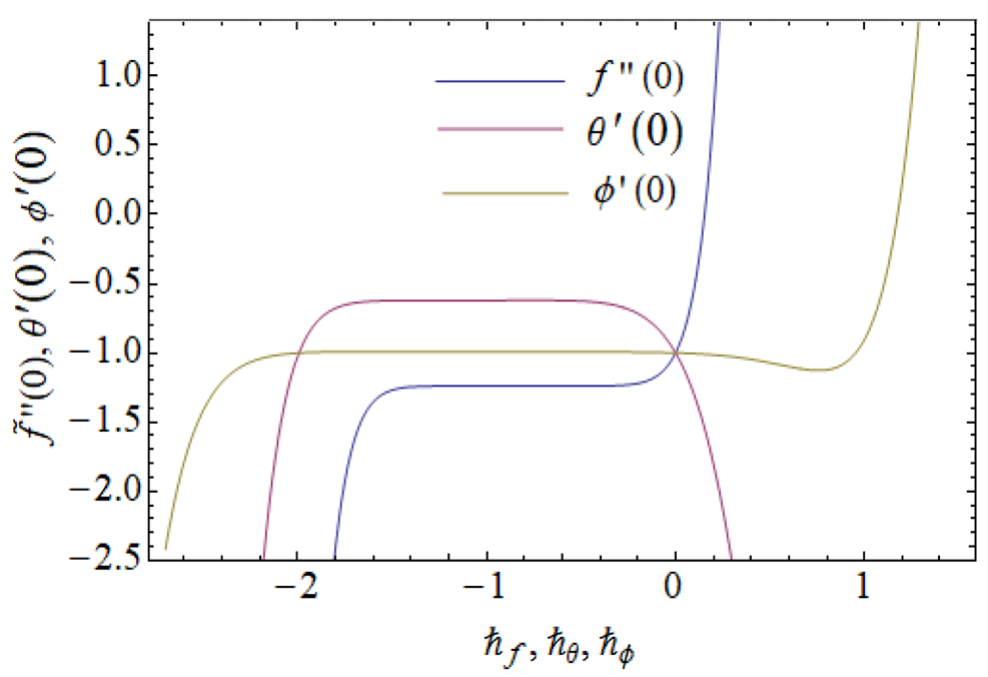

Fig. 2. $\hbar$-curves for $f^{\prime \prime}(0), \theta^{\prime}(0)$ and $\phi^{\prime}(0)$.

\subsection{Bejan number}

We have

$$
B e=\frac{\text { Entropy generation due to heat and mass transfer }}{\text { Total entropy generation }}
$$

or

$$
B e=\frac{\left[1+R\left(\theta\left(\theta_{w}-1\right)+1\right)^{3}\right] \theta^{\prime 2} \alpha_{1}+L \frac{\alpha_{2}}{\alpha_{1}} \phi^{\prime 2}+L \theta^{\prime} \phi^{\prime}}{\left[1+R\left(\theta\left(\theta_{w}-1\right)+1\right)^{3}\right] \theta^{\prime 2} \alpha_{1}+B r(1-s) f^{\prime \prime 2}+B r \frac{W e}{2} f^{\prime \prime 3}+M B r f^{\prime 2}+L \frac{\alpha_{2}}{\alpha_{1}} \phi^{\prime 2}+L \theta^{\prime} \phi^{\prime}} .
$$

\section{Convergence analysis}

We used HAM [47] for convergent solutions of the problem. In this method, auxiliary parameters are involved which gave us freedom to adjust the convergence region for $f^{\prime \prime}(0), \theta^{\prime}(0)$ and $\phi^{\prime}(0)$. Convergent regions parallel to the $\hbar$-axis are $-1.3 \leq \hbar_{f} \leq-0.4$ and $-1.6 \leq \hbar_{\theta} \leq-0.8$ and $-1.8 \leq \hbar_{\phi} \leq-0.2$.

One can see that the convergence of $f^{\prime \prime}(0), \theta^{\prime}(0)$ and $\phi^{\prime}(0)$ is achieved at the 8th, 17th and 24th order of approximations, respectively (see table 1$)$. Figure 2 is plotted for the $\hbar$-curves. 
Table 2. Numerical computations of surface drag force when $\lambda=\beta_{t}=\beta_{c}=W e=\delta=0.1, E c=\varepsilon=\sigma_{1}=0.1, \theta_{w}=1.1$, $M=0.5, s=0.3, N t=N^{*}=N b=S c=0.01, R=0.2, \operatorname{Pr}=2$.

\begin{tabular}{|c|c|c|c|}
\hline$W e$ & $s$ & $\lambda$ & $\frac{1}{2} C_{f} \mathrm{R}^{\frac{1}{2}}$ \\
\hline 0.1 & 0.1 & 0.1 & 0.00857 \\
\hline 0.3 & & & 0.02642 \\
\hline 0.5 & & & 0.04529 \\
\hline 0.1 & 0.2 & & 0.01842 \\
\hline & 0.3 & & 0.03015 \\
\hline & 0.1 & 0.2 & 0.007474 \\
\hline & & 0.3 & 0.006495 \\
\hline
\end{tabular}

Table 3. Heat transfer rate when $\lambda=\beta_{t}=\beta_{c}=W e=\delta=0.1, E c=\varepsilon=\sigma_{1}=0.1, \theta_{w}=1.1, M=0.5, s=0.3$, $N t=N^{*}=N b=S c=0.01, R=0.2, \operatorname{Pr}=2$.

\begin{tabular}{|c|c|c|c|}
\hline$\theta_{w}$ & $N t$ & $E c$ & $N u_{x} \operatorname{Re}^{-\frac{1}{n+1}}$ \\
\hline 1.1 & 0.01 & 0.1 & 0.7860 \\
\hline 1.2 & & & 0.7980 \\
\hline 1.3 & & & 0.8130 \\
\hline 1.1 & 0.1 & & 0.7300 \\
\hline & 0.2 & & 0.6730 \\
\hline & 0.01 & 0.2 & 0.6650 \\
\hline & & 0.3 & 0.5450 \\
\hline
\end{tabular}

Table 4. Sherwood number when $\lambda=\beta_{t}=\beta_{c}=W e=\delta=0.1, E c=\varepsilon=\sigma_{1}=0.1, \theta_{w}=1.1, M=0.5, s=0.3$, $N t=N^{*}=N b=S c=0.01, R=0.2, \operatorname{Pr}=2$.

\begin{tabular}{|c|c|c|c|c|}
\hline$S c$ & $N t$ & $\sigma_{1}$ & $v$ & $S h_{x} \mathrm{Re}^{-\frac{1}{n+1}}$ \\
\hline 0.01 & 0.01 & 0.1 & 0.1 & 0.9962 \\
\hline 0.02 & & & & 1.0020 \\
\hline 0.03 & & & & 1.0080 \\
\hline 0.01 & 0.1 & & & 0.9356 \\
\hline & 0.2 & & & 0.8871 \\
\hline & 0.01 & 0.2 & & 1.0410 \\
\hline & & 0.3 & & 1.1530 \\
\hline & & 0.1 & 0.2 & 0.9941 \\
\hline & & & 0.3 & 0.9923 \\
\hline
\end{tabular}

Table 5. Comparison values of $f^{\prime \prime}(0)$ with refs. [49] and [50] when $W e=s=\lambda=N^{*}=\beta_{t}=\beta_{c}=0$.

\begin{tabular}{|c|c|c|c|}
\hline$M$ & ref. [49] & ref. [50] & Present \\
\hline 0.0 & -1.0000 & -1.0000 & -1.0000 \\
\hline 0.5 & -1.1803 & -1.18034 & -1.18034 \\
\hline 1.0 & -1.41421 & -1.414214 & -1.414214 \\
\hline
\end{tabular}

\section{Discussion}

After formulating the mathematical modeling of the problem, we reduced the system of PDEs having cylindrical symmetry to a system of ODEs for all observables in terms of the vertical coordinate. The auxiliary problem and the related series expansion are then analytically studied to examine the variation of the entropy as a function of 


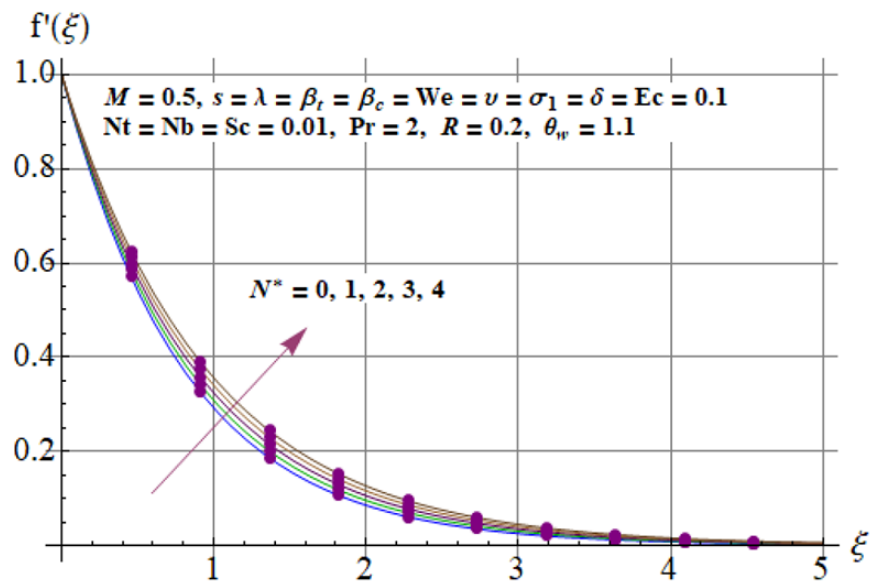

Fig. 3. $f^{\prime}(\xi)$ against $N^{*}$.

$\mathrm{f}^{\prime}(\xi)$

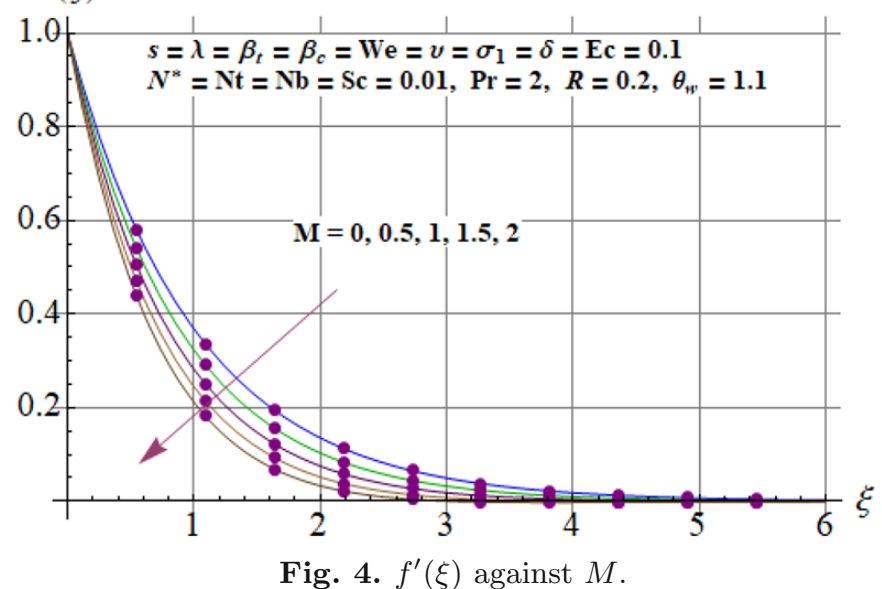

different parameters which include Weissenberg number $(W e)$, velocity ratio variable $(A)$, Hartman number $(M)$, mixed convection parameter $(\lambda)$, nonlinear mixed convection parameter for temperature $\left(\beta_{t}\right)$, concentration and thermal buoyancy forces ratio $\left(N^{*}\right)$, nonlinear mixed convection variable for concentration $\left(\beta_{c}\right)$, Prandtl number $(\operatorname{Pr})$, radiation parameter $(R)$, Eckert number $(E c)$, Grashof number for temperature and concentration $\left(G r_{x}\right)$ and $\left(G r_{x}^{*}\right)$, temperature ratio parameter $\left(\theta_{w}\right)$, thermophoresis variable $(N t)$, Schmidt number $(S c)$, Brownian motion parameter $(N b)$, heat generation/absorption variable $\left(\delta^{*}\right)$, chemical reaction variable $\left(\sigma_{1}\right)$, temperature relative parameter $(\delta)$, activation energy variable $(v)$, temperature difference parameter for entropy $\left(\alpha_{1}\right)$, Brinkman number $(B r)$, concentration difference variable $\left(\alpha_{2}\right)$, diffusion variable $(L)$ and local entropy generation $\left(N_{G}\right)$. The resulted graphs for velocity, temperature, concentration and entropy number are displayed in figs. 3-33. Table 1 highlights the computational results of $f^{\prime \prime}(0), \theta^{\prime}(0)$ and $\phi^{\prime}(0)$ for convergence series solutions. Table 1 shows that the 8 th, 17 th and 24 th order of approximations fulfill the convergence requirement of $f^{\prime \prime}(0), \theta^{\prime}(0)$ and $\phi^{\prime}(0)$. Table 2 represents the impact of various flow parameters like stretching variable $(s)$, Weissenberg number $(W e)$ and $(\lambda)$ on skin friction coefficient (surface drag force). In table 2 , it can be observed that the magnitude of $\left(C_{f}\right)$ is higher for a larger Weissenberg number and stretching variable. Table 3 represents the impact of $\left(\theta_{w}\right),(N t)$ and $(E c)$ on the Nusselt number. Similarly, it can be observed that with the higher estimations of $\left(\theta_{w}\right)$, the $\left(N u_{x}\right)$ increases, while it decreases for larger $(N t)$ and $(E c)$. Table 4 displays the influence of $(S c),(N t),\left(\sigma_{1}\right)$ and $(v)$ on the Sherwood number. The results indicate that the mass transfer increases for higher estimations of the Schmidt number and chemical reaction variable while inverse behavior exists for activation energy and thermophoresis. Table 5 shows agreement with the previous literature for numerical values of $f^{\prime \prime}(0)$.

\subsection{Velocity distribution}

Figures 3-7 show the impact of $\left(N^{*}\right),(M),(\lambda),\left(\beta_{t}\right)$ and Weissenberg number $(W e)$ on $\left(f^{\prime}(\xi)\right)$. Figure 3 elucidates the behavior of $\left(f^{\prime}(\xi)\right)$ when $N^{*}=0,1,2,3,4$. It is noted that the fluid motion is faster for larger $\left(N^{*}\right)$. Figure 4 


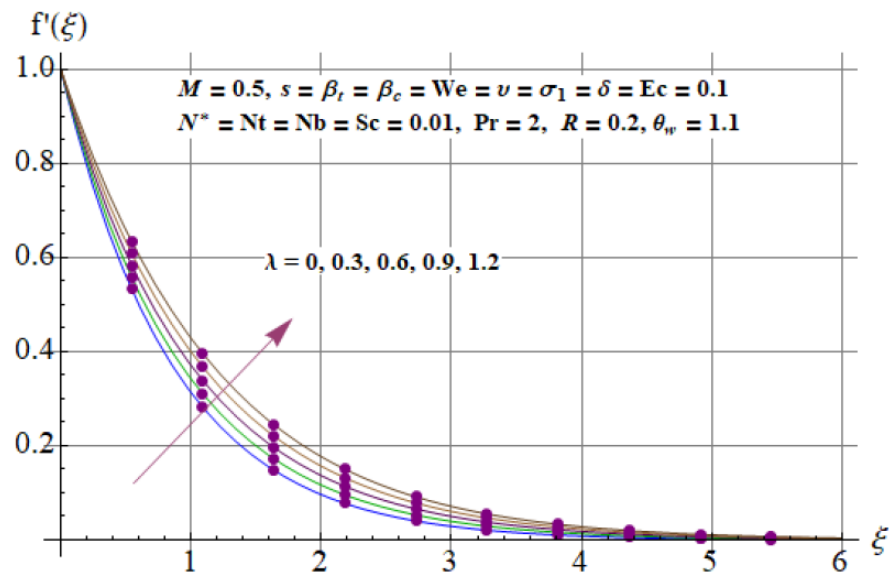

Fig. 5. $f^{\prime}(\xi)$ against $\lambda$.

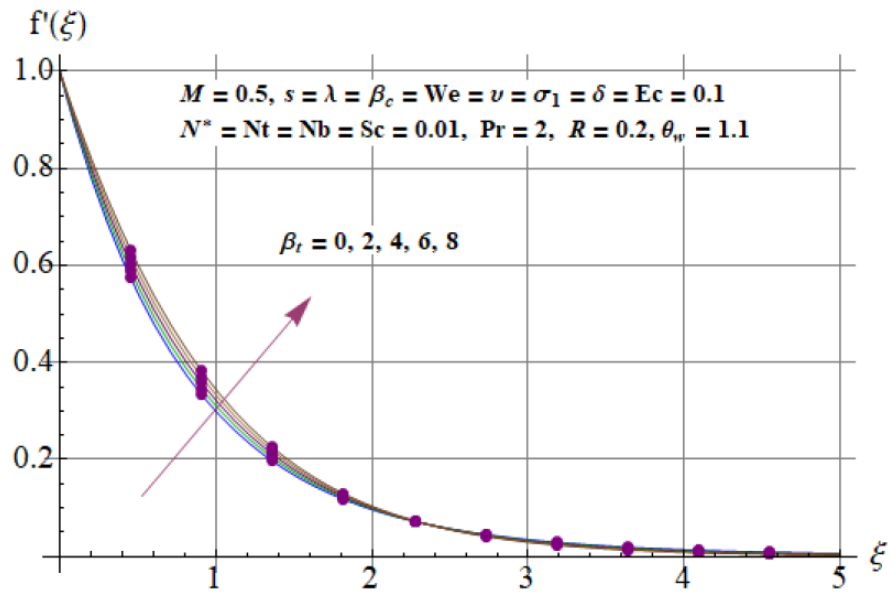

Fig. 6. $f^{\prime}(\xi)$ against $\beta_{t}$.

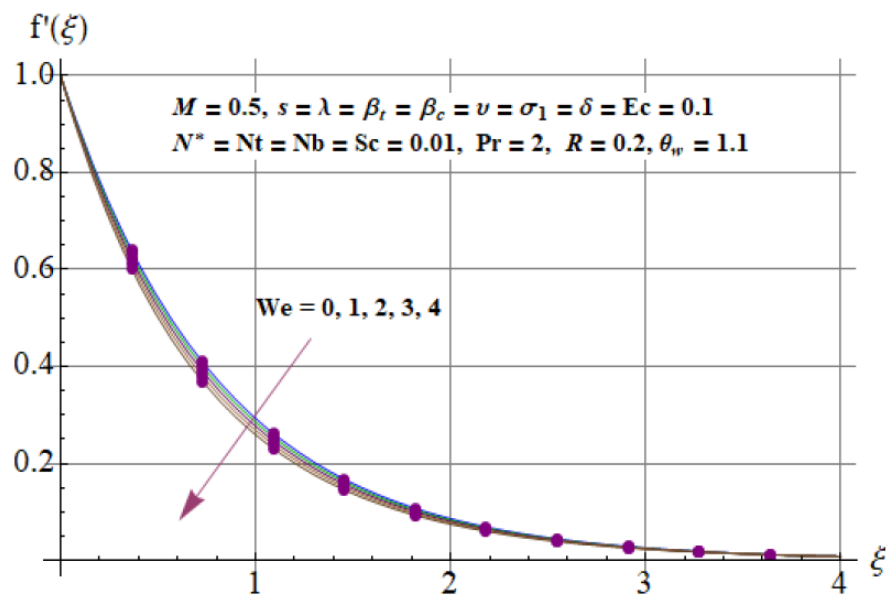

Fig. 7. $f^{\prime}(\xi)$ against $W e$.

examines the decreasing trend of $\left(f^{\prime}(\xi)\right)$ for higher $M=0,0.5,1,1.5,2$. Since $(M)$ is dependent on the Lorentz force, for larger $(M)$ the resistance between the liquid particles increases which helps to reduce $\left(f^{\prime}(\xi)\right)$. The influence of $(\lambda)$ on $\left(f^{\prime}(\xi)\right)$ is shown in fig. 5. For larger $\lambda=0,0.3,0.6,0.9,1.2$ the velocity $\left(f^{\prime}(\xi)\right)$ increases. The ratio of buoyancy to viscous forces is known as mixed convection $(\lambda)$. For larger values of $(\lambda)$, the viscous forces remain low which results in the increase of velocity. The behavior of $\left(f^{\prime}(\xi)\right)$ for larger nonlinear mixed convection parameter $\left(\beta_{t}\right)$ is shown in 


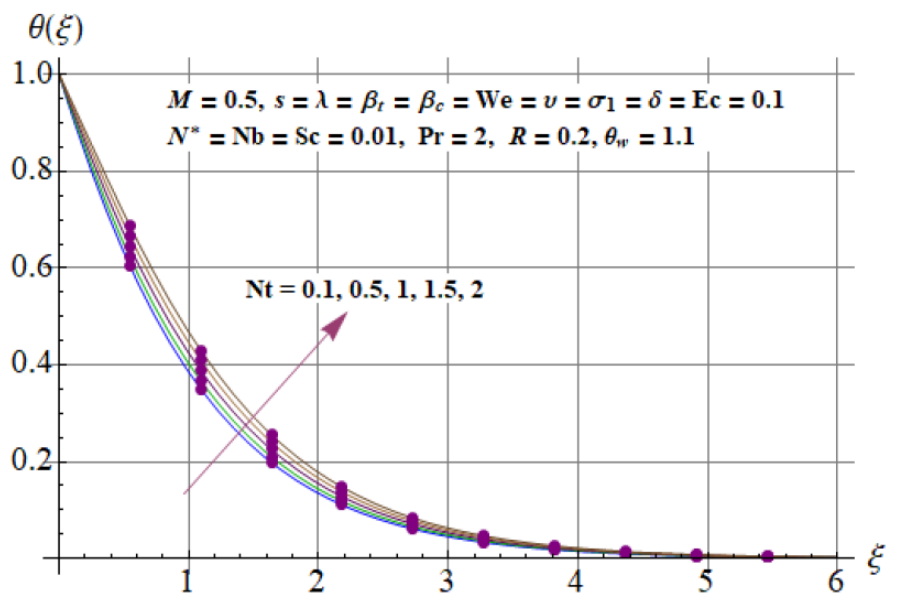

Fig. 8. $\theta(\xi)$ against $N t$.

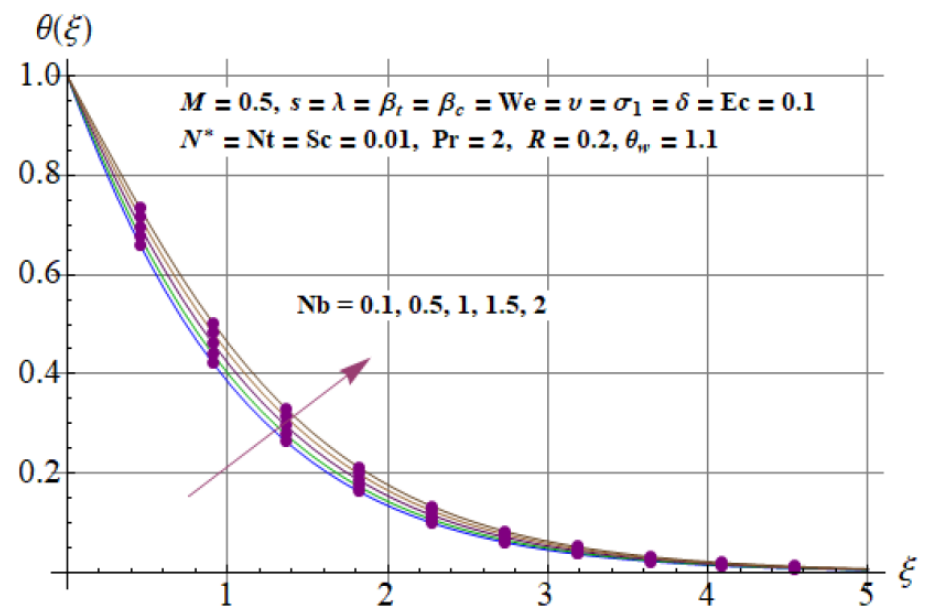

Fig. 9. $\theta(\xi)$ against $N b$.

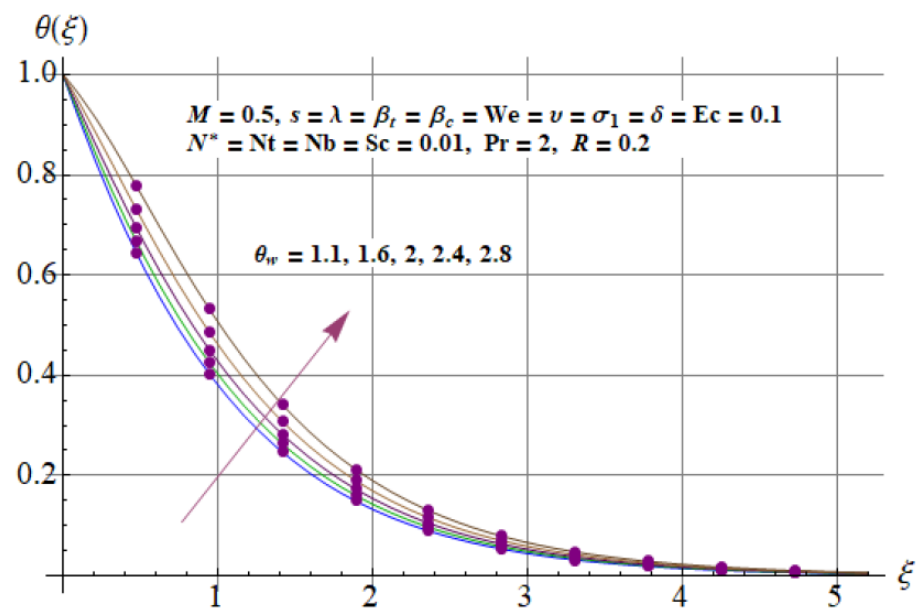

Fig. 10. $\theta(\xi)$ against $\theta_{w}$.

fig. 6. It can be observed that the motion of fluid particles increases for higher $\beta_{t}=0,2,4,6,8$. In fact, for higher $\left(\beta_{t}\right)$ the temperature difference $\left(T_{w}-T_{\infty}\right)$ increases which is responsible for the enhancement of velocity. Figure 7 examines the impact of Weissenberg number $W e=0,1,2,3,4$ on $\left(f^{\prime}(\xi)\right)$. We can see that the fluid motion gradually reduces for larger $(W e)$. 


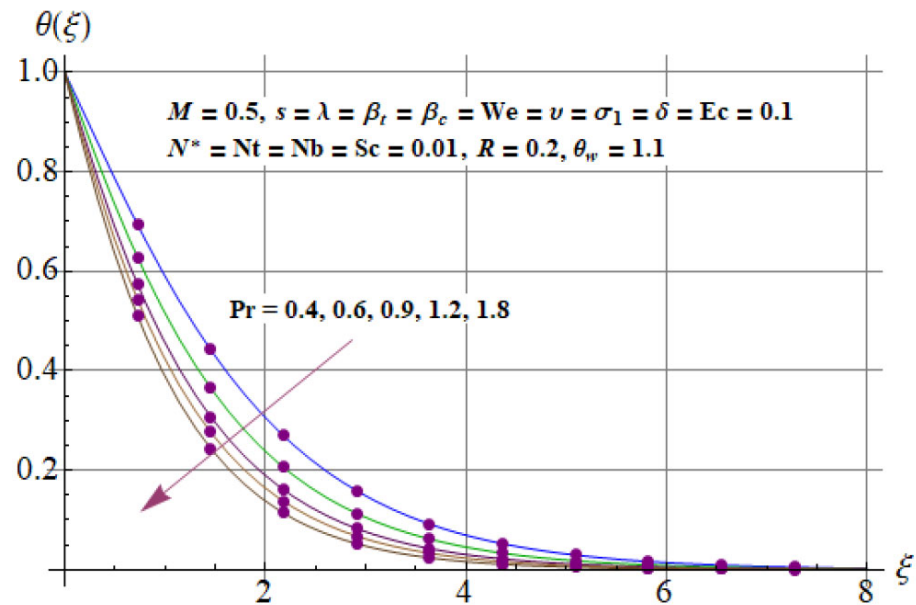

Fig. 11. $\theta(\xi)$ against $\operatorname{Pr}$.

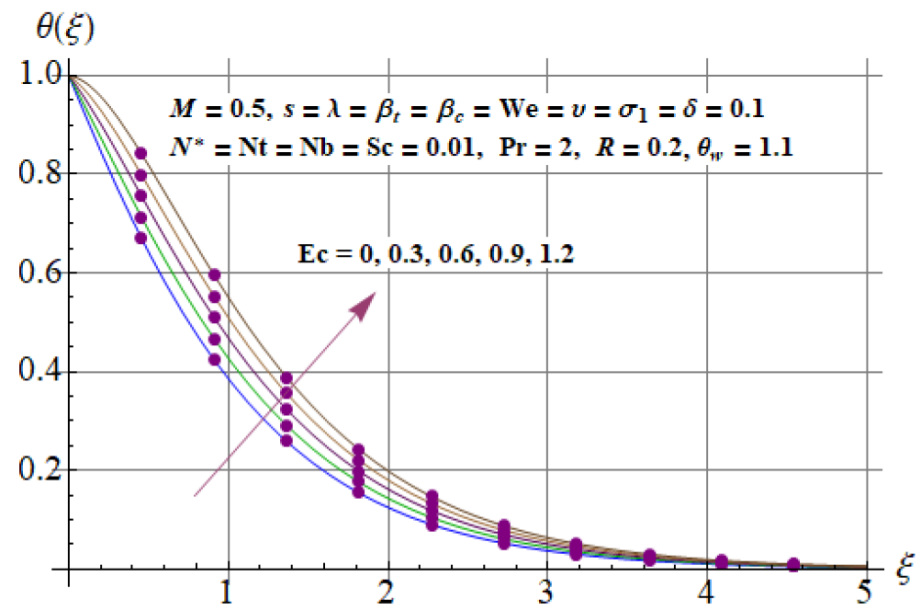

Fig. 12. $\theta(\xi)$ against $E c$.

$\theta(\xi)$

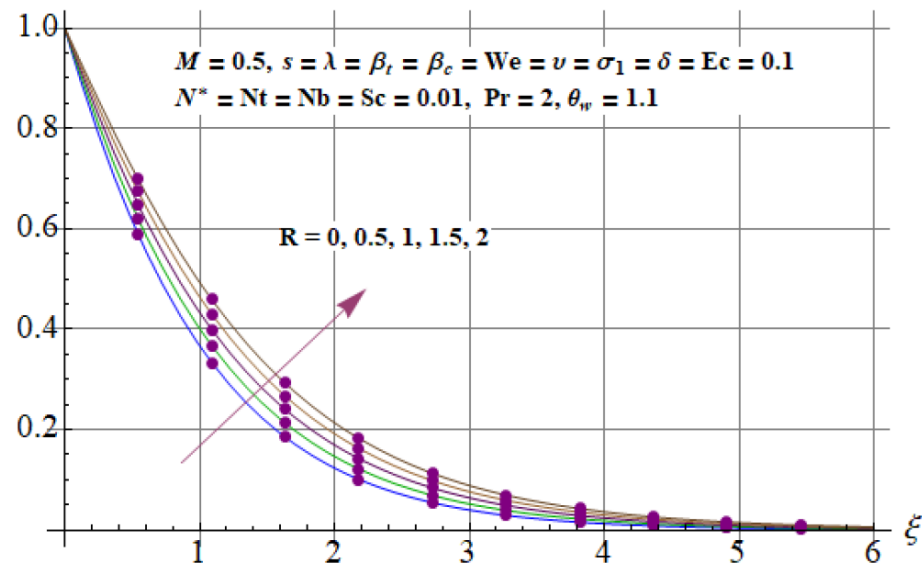

Fig. 13. $\theta(\xi)$ against $R$.

\subsection{Temperature distribution}

Figures 8-13 are sketched to analyze $(\theta(\xi))$ against $(N t),(N b),\left(\theta_{w}\right),(\operatorname{Pr}),(E c)$ and $(R)$. Variations of $N t=0.1$, $0.5,1,1.5,2$ and $N b=0.1,0.5,1,1.5,2$ for temperature distribution $(\theta(\xi))$ is shown in figs. 8 and 9 . A similar behavior of both parameters is noticed with respect to the variation of temperature and thermal layer thickness. It is observed that the movement of fluid particles rises from hot to cold regions for larger $(N t)$ (see fig. 8). For higher 
$\phi(\xi)$

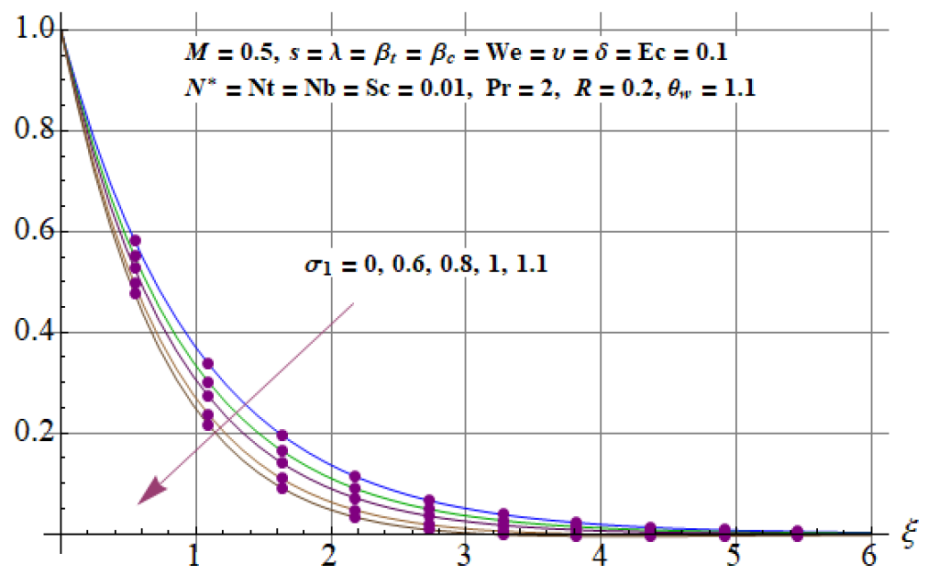

Fig. 14. $\phi(\xi)$ against $\sigma_{1}$.

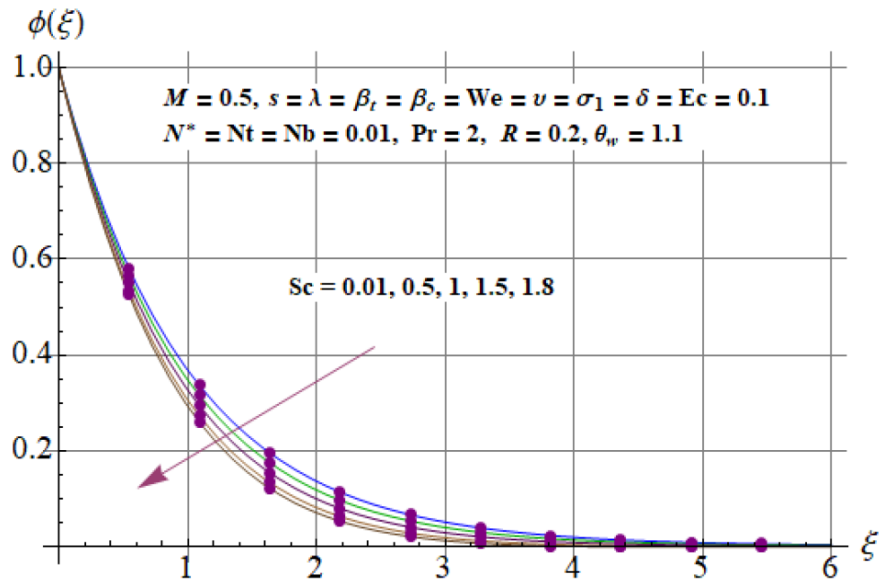

Fig. 15. $\phi(\xi)$ against $S c$.

$\phi(\xi)$

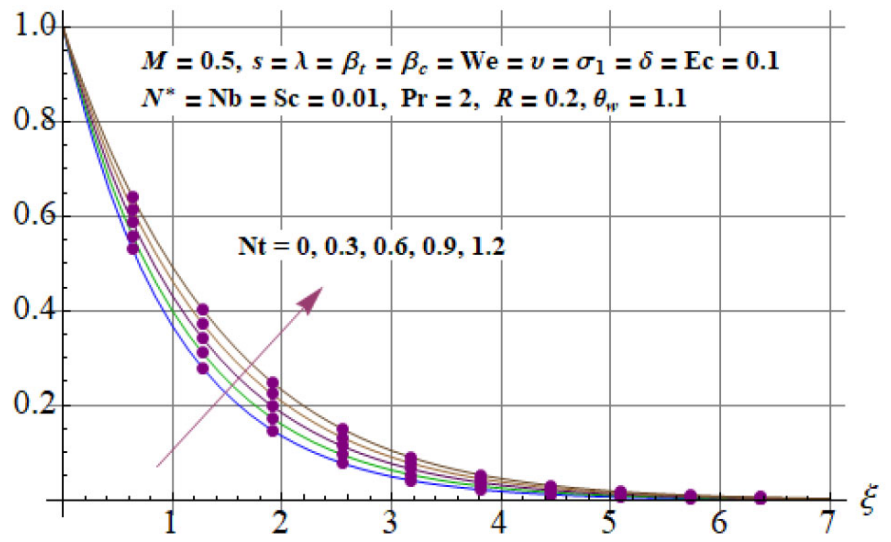

Fig. 16. $\phi(\xi)$ against $N t$.

estimations of $(\mathrm{Nb})$ the random motion of fluid particles enhances and so temperature increases (see fig. 8). For a larger temperature ratio, the parameter $\theta_{w}=1.1,1.6,2,2.4,2.8$, the increasing trend in fluid temperature $(\theta(\xi))$ is noticed (see fig. 10). Figure 11 shows the impact of $\operatorname{Pr}=0.4,0.6,0.9,1.2,1.5$ on $(\theta(\xi))$. One can observe that $(\theta(\xi))$ work as a decreasing function of Pr. Figures 12 and 13 display the impact of Eckert number $E c=0,0.3,0.6,0.9,1.2$ and radiation parameter $R=0,0.5,1,1.5,2$ on temperature $(\theta(\xi))$. For larger $(E c)$ the fluid temperature increases. 


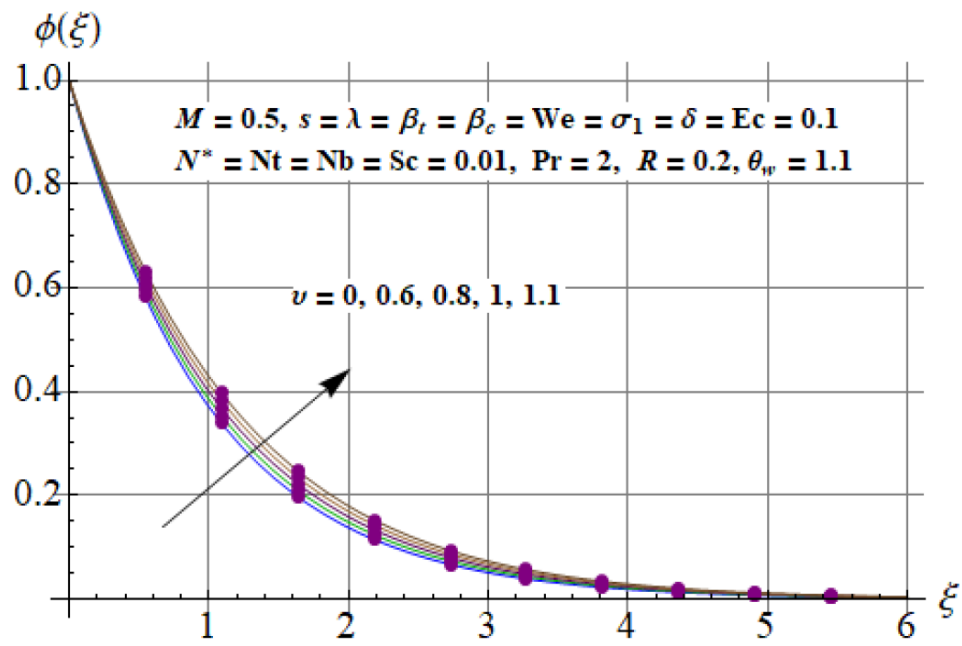

Fig. 17. $\phi(\xi)$ against $v$.

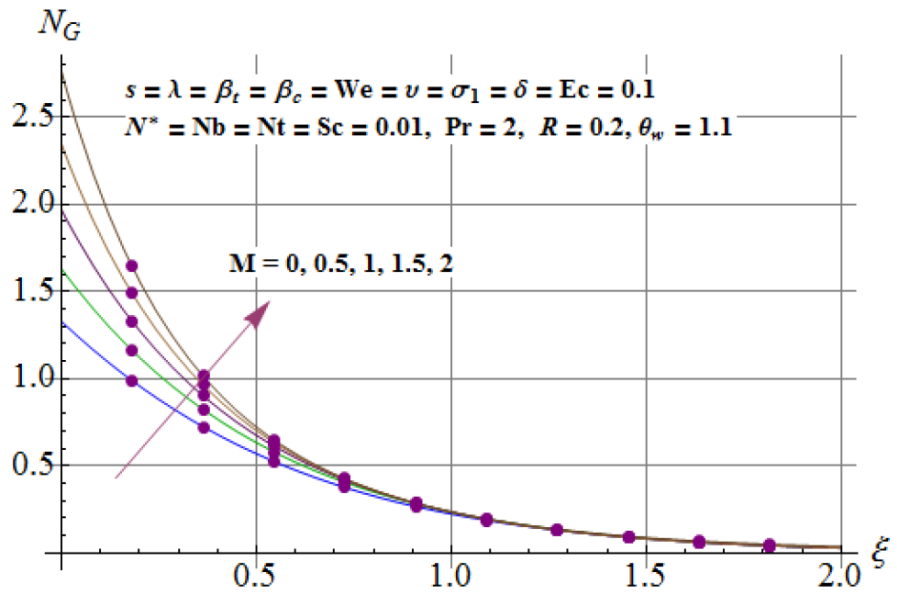

Fig. 18. $N_{G}(\xi)$ against $M$.

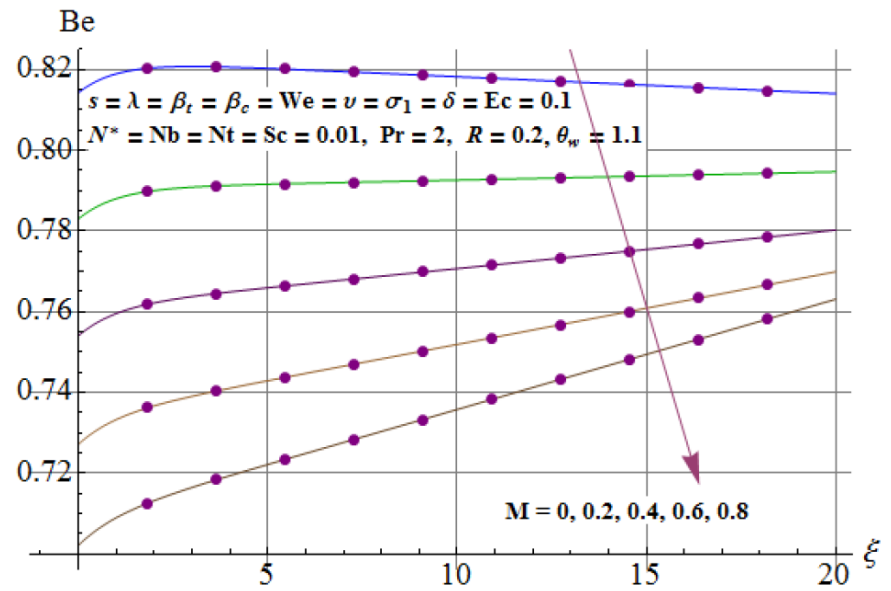

Fig. 19. $B e$ against $M$.

For an increase in $(E c)$ the friction inside fluid changes mechanical energy to thermal energy and as a result $(\theta(\xi))$ increases (see fig. 12). An increasing trend of $(\theta(\xi))$ is noticed for larger $(R)$. Temperature increases due to a decay in the mean absorption coefficient for larger $(R)$ (see fig. 13). 


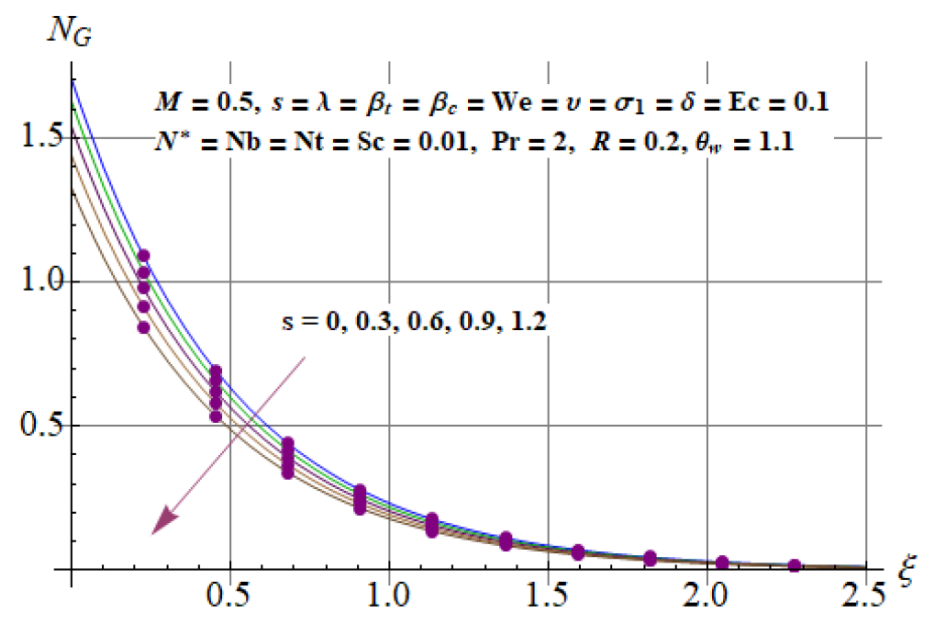

Fig. 20. $N_{G}(\xi)$ against $s$.

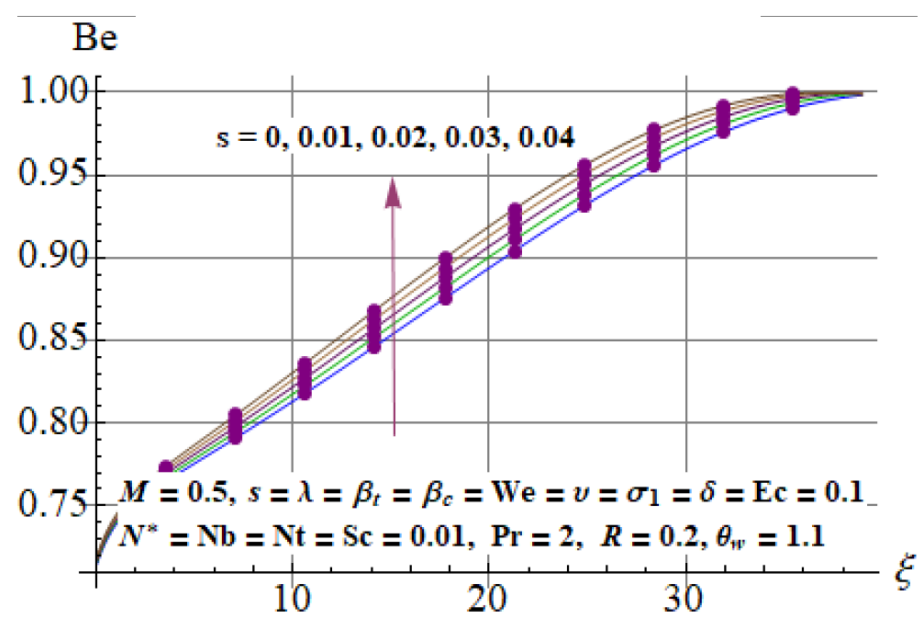

Fig. 21. Be against $s$.

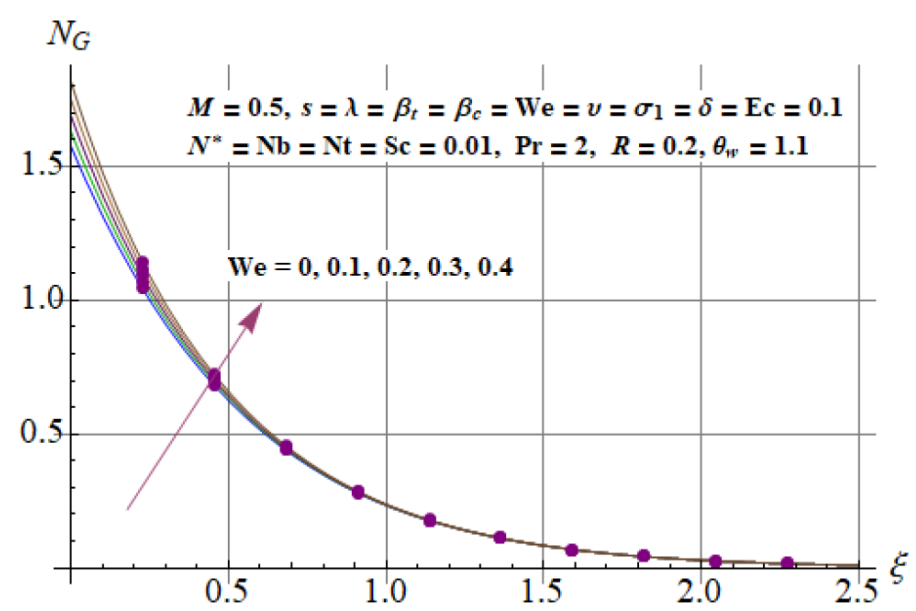

Fig. 22. $N_{G}(\xi)$ against $W e$.

\subsection{Concentration}

Figures 14-17 examine the influences of chemical reaction rate constant $\left(\sigma_{1}\right)$, Schmidt number $(S c)$, thermophoresis parameter $(N t)$, Brownian motion parameter $(N b)$ and activation energy parameter $(v)$. The influence of chemical reaction rate parameter $\sigma_{1}=0,0.6,0.8,1,1.5$ is plotted in fig. 14. The decreasing impact of $(\phi(\xi))$ is seen for larger $\left(\sigma_{1}\right)$. Physically, for larger $\left(\sigma_{1}\right)$ the destructive rate of chemical reaction increases. It is used to dissolve the liquid specie 


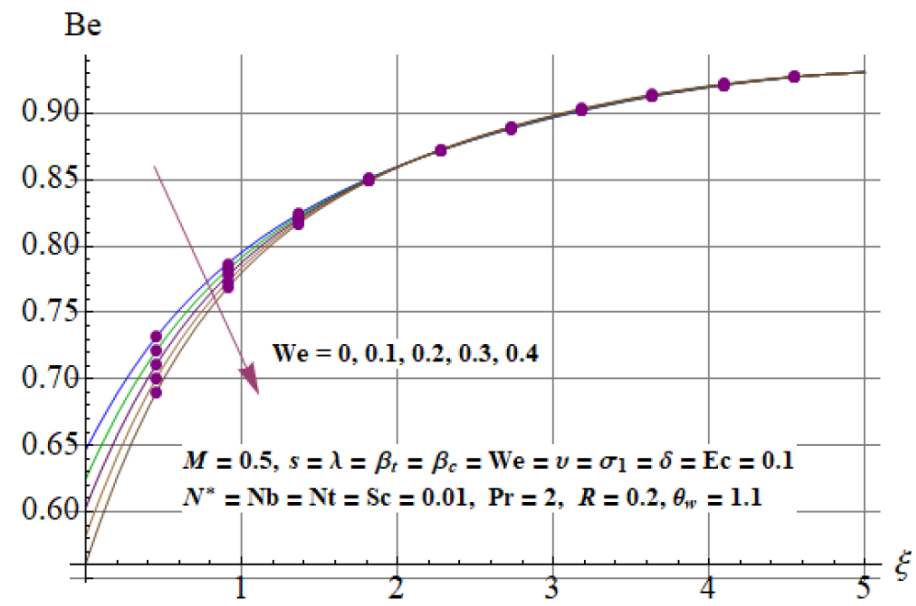

Fig. 23. Be against $W e$.

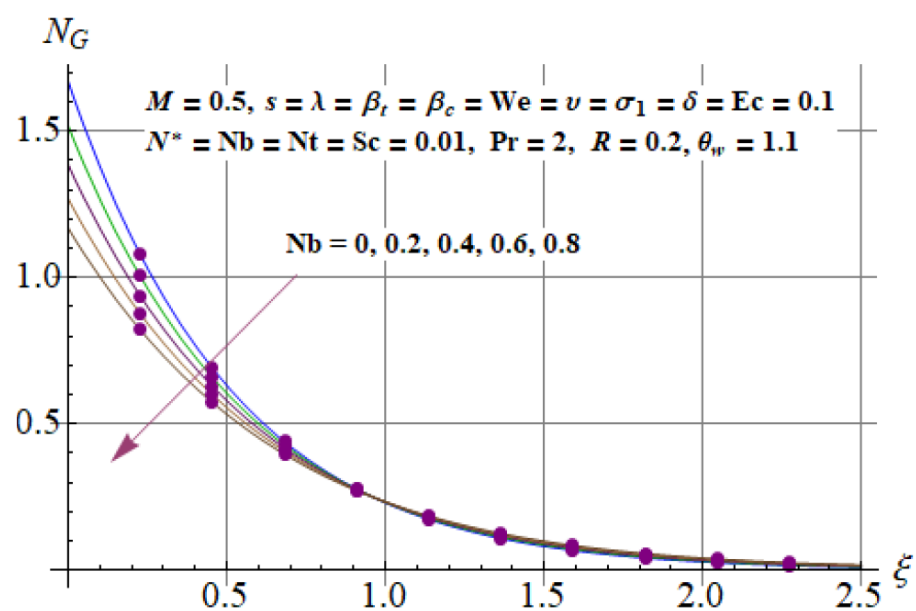

Fig. 24. $N_{G}(\xi)$ against $N b$.

$\mathrm{Be}$

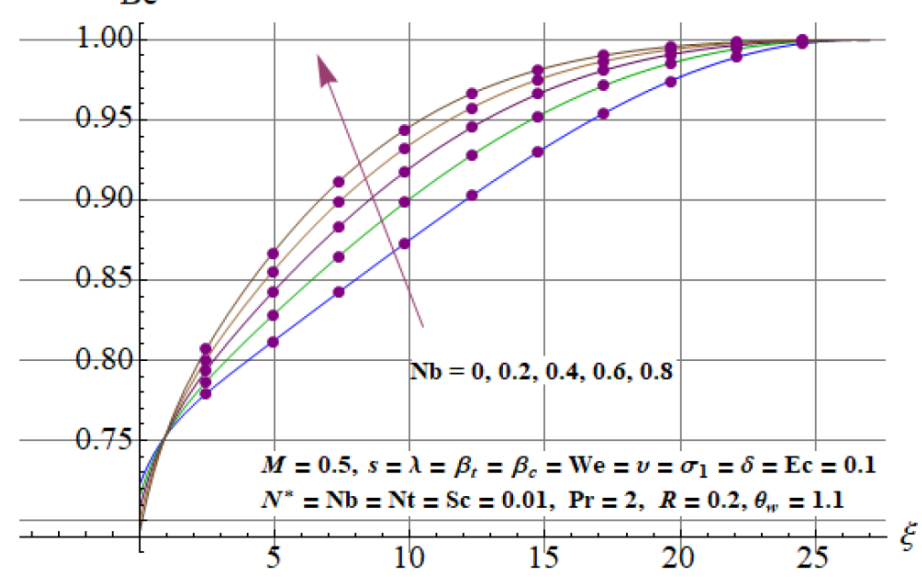

Fig. 25. Be against $N b$.

more effectively. Figure 15 shows the impact of Schmidt number $S c=0.01,0.5,1,1.5,1.8$ on concentration $(\phi(\xi))$. A decreasing trend is noticed for larger $(S c)$. Due to a decrease in mass diffusivity for larger $(S c)$ the concentration and associated layers are decreased. Figures 16 and 17 are plotted to examine concentration for larger thermophoresis parameter $(N t)$ and activation energy $(v)$. Here, an increasing behavior exists for both parameters at concentration values. Physically, higher $v=0,0.6,0.8,1,1.1$ decrease the modified Arrhenius function and it leads to the promotion of a generative chemical reaction. As a result, there is an enhancement of $(\phi(\xi))$ (see fig. 17). 


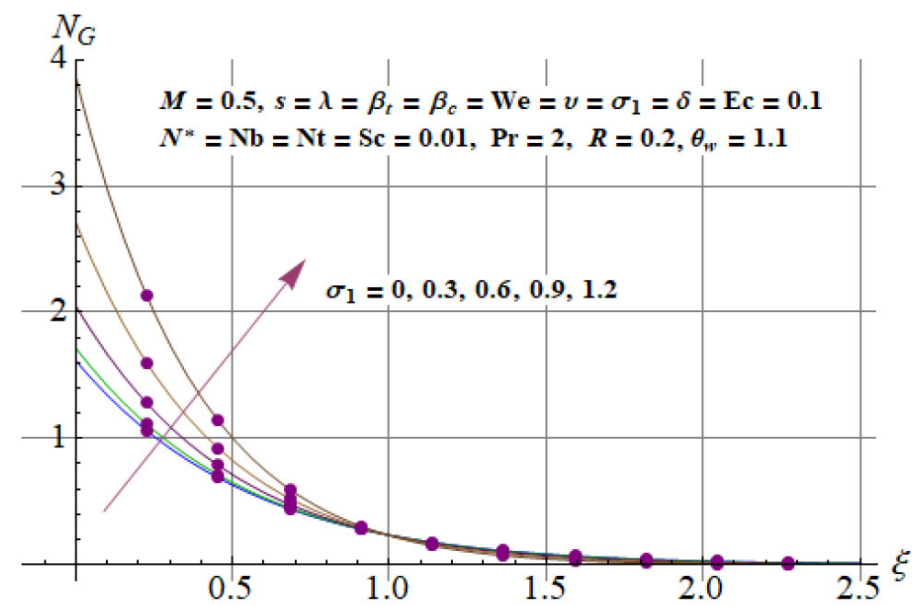

Fig. 26. $N_{G}(\xi)$ against $\sigma_{1}$.

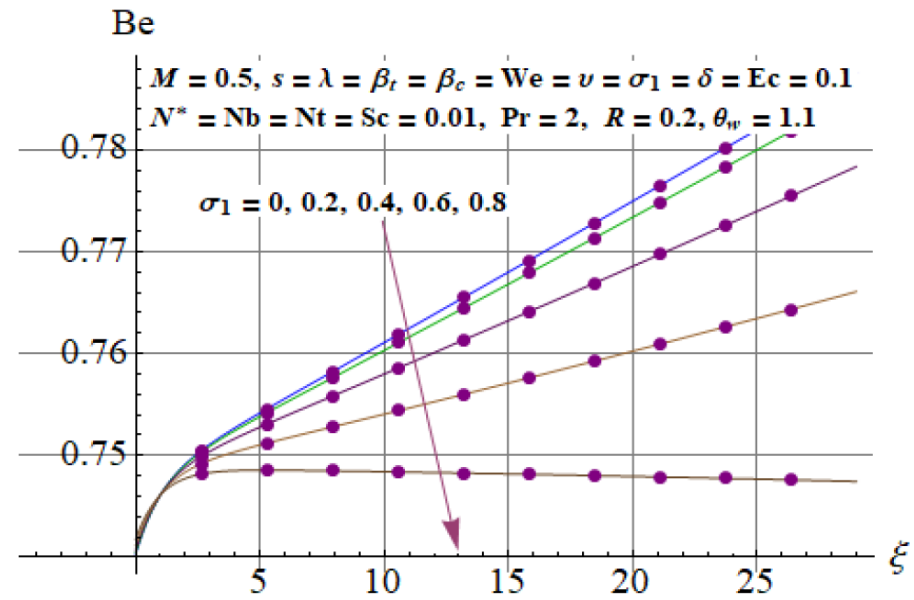

Fig. 27. $B e$ against $\sigma_{1}$.

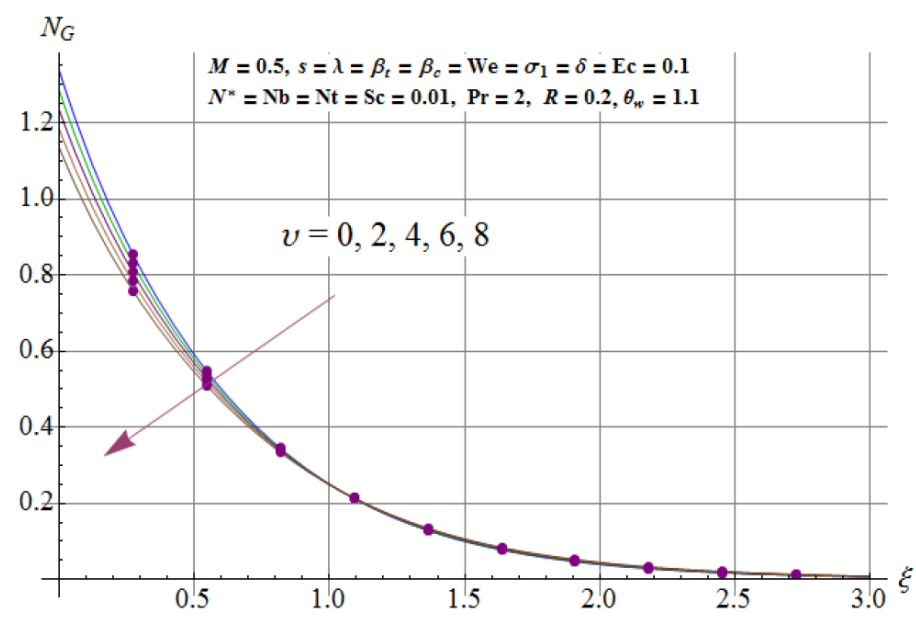

Fig. 28. $N_{G}(\xi)$ against $v$.

\subsection{Entropy and Bejan numbers}

Figures 18-33 are sketched to analyze entropy $\left(N_{G}\right)$ and Bejan $(B e)$ numbers for larger Hartman number $(M)$, power law index $(s)$, Weissenberg number $(W e)$, chemical reaction rate variable $\left(\sigma_{1}\right)$, Brownian motion parameter $(N b)$, activation energy variable $(v)$, Brinkman number $(B r)$ and diffusion variable $(L)$. Salient features of Hartman number $(M)$ on $\left(N_{G}\right)$ and $(B e)$ are shown through figs. 18 and 19. An increasing trend of entropy generation $\left(N_{G}\right)$ is observed 


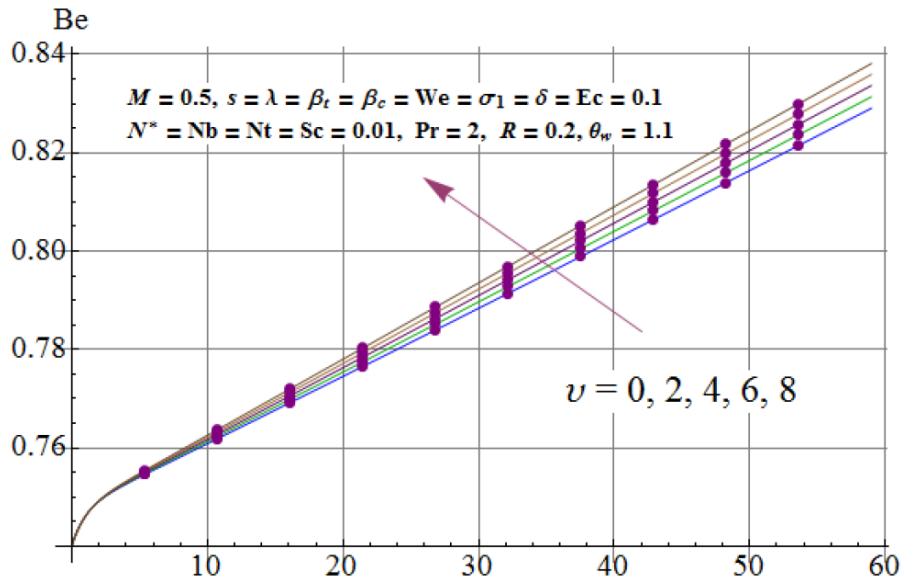

Fig. 29. Be against $v$.

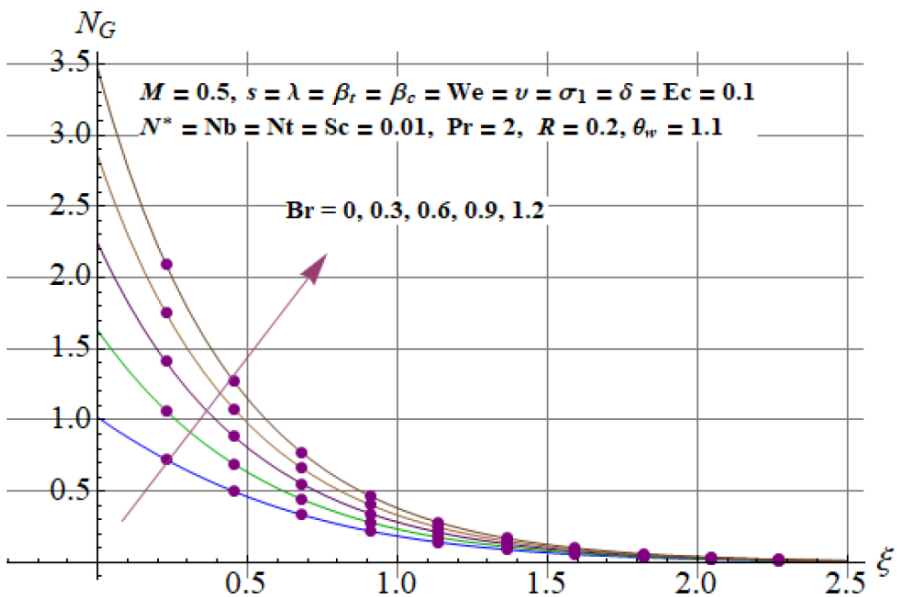

Fig. 30. $N_{G}(\xi)$ against $B r$.

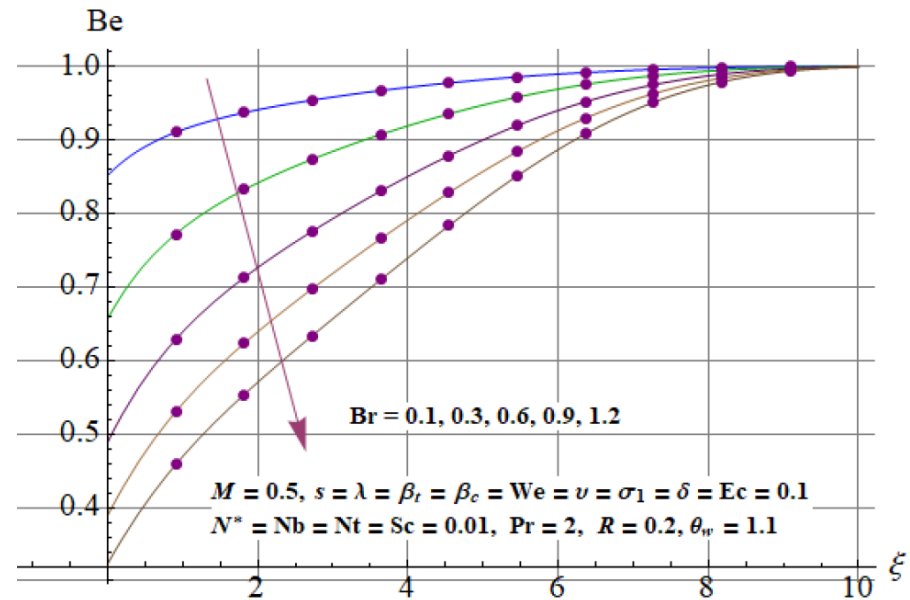

Fig. 31. $B e$ against $B r$.

while an opposite impact of Bejan number $(B e)$ is noticed. Due to an increase in resistance for larger $(M)$ the entropy generation enhances (see fig. 18). Clearly viscous effects are dominated over heat and mass transfer effects which is the possible cause for the reduction in $(B e)$ values. Figures 20 and 21 are plotted to examine $\left(N_{G}\right)$ and $(B e)$ for power law index $(s)$. Through higher estimation of $(s)$ the entropy generation $\left(N_{G}\right)$ reduces while an increasing trend is observed for higher $(s)$. For larger $(s)$ the heat and mass transport impacts are higher than viscous effects and so $(B e)$ enhances (see fig. 21). The influence of Weissenberg number $(W e)$ on $\left(N_{G}\right)$ and $(B e)$ is shown in figs. 22 and 23 . The entropy 


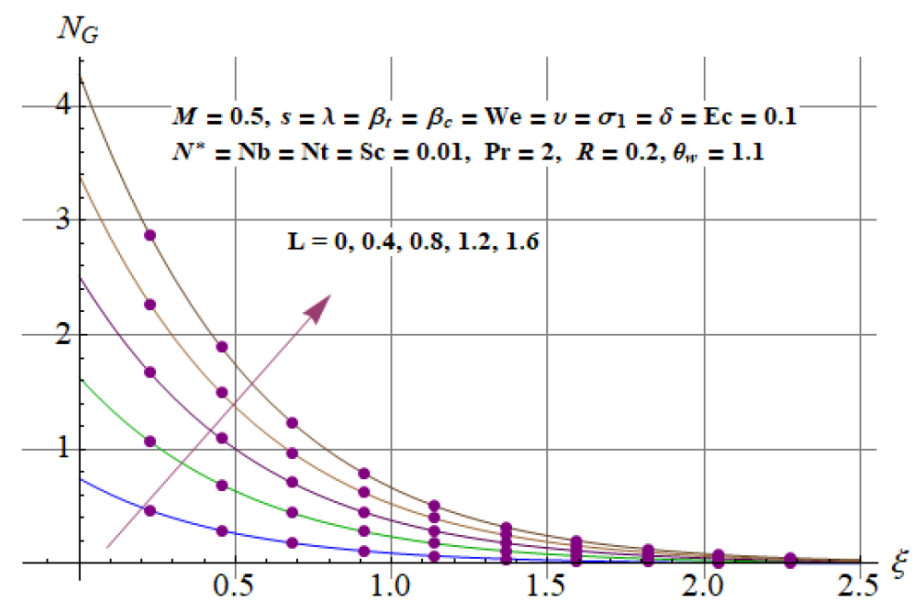

Fig. 32. $N_{G}(\xi)$ against $L$.

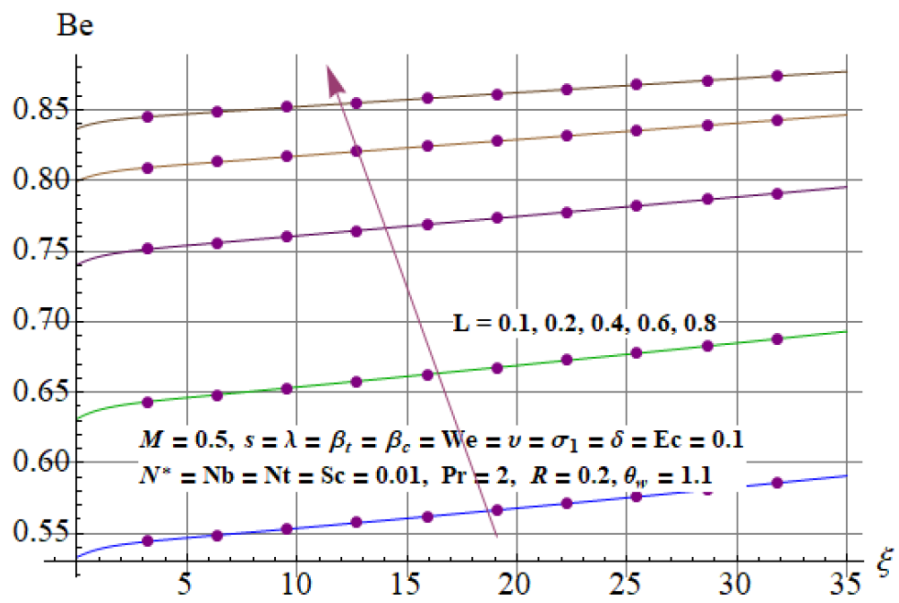

Fig. 33. Be against $L$.

generation rate enhances for larger $(W e)$ (see fig. 22). Physically, for higher (We) relaxation time increases which means that there is more resistance between fluid particles. Resulting heat loss enhances $\left(N_{G}\right)$. On the other hand, a reverse impact is seen for Bejan number $(B e)$ because heat and mass transport effects are dominant for larger $(W e)$. Figures 24 and 25 show the behavior of Brownian motion parameter $(N b)$ on $\left(N_{G}\right)$ and $(B e)$. There is a reduction in $\left(N_{G}\right)$ for larger $(N b)$. However, an behavior is noticed for $(B e)$ through $(N b)$. We can see that for higher estimations of $(N b)$, the concentration difference increases so $(B e)$ is enhanced. Figures 26 and 27 reveal that for a stronger chemical reaction rate variable $\left(\sigma_{1}\right)$, the $\left(N_{G}\right)$ and $(B e)$ have increasing and decreasing effects respectively. For higher $\left(\sigma_{1}\right)$, the chemical reaction rate $\left(k_{r}\right)$ gradually increases which is responsible for a surge in $\left(N_{G}\right)$ (see fig. 26). Characteristics of activation energy parameter $(v)$ on $\left(N_{G}\right)$ and $(B e)$ are presented in figs. 28 and 29. Entropy rate can be observed as a decreasing function of activation energy (see fig. 28). However, increasing values of $(v)$ reduce the Bejan number $(B e)$ (see fig. 29). Similarly, in fig. 30, $\left(N_{G}\right)$ work as an increasing function of $(B r)$. In fig. 31, the Bejan number has an opposite effect on $(B r)$. Actually, a large amount of heat is generated for higher $(B r)$ which subsequently enhances the value of $\left(N_{G}\right)$. It can be seen that for larger $(B r)$ the heat and mass transfer irreversibilities are less than viscous effects so $(B e)$ reduces (see fig. 31$)$. Figures 32 and 33 show the effect of diffusion parameter $(L)$ on $\left(N_{G}\right)$ and $(B e)$. One can see that for larger values of $(L)$ both $\left(N_{G}\right)$ and $(B e)$ are increased.

\section{Final remarks}

The key points of the present communication are listed below.

- Skin friction coefficient $\left(C_{f x}\right)$ enhances for higher Weissenberg number and stretching parameter.

- Magnitude of Nusselt number $\left(N u_{x}\right)$ is increased for a larger thermophoresis parameter while it decreases for higher Eckert number. 
- For a larger estimation of the chemical reaction variable and Schmidt number there is an increase in the magnitude of Sherwood number $\left(S h_{x}\right)$.

- Velocity of fluid particle decreases for larger Hartman number.

- An increase is observed for temperature on the higher values thermophoresis and Brownian diffusions.

- Temperature decreases for Prandtl number (Pr).

- Entropy number $\left(N_{G}\right)$ is increased for higher Hartman number $(M)$.

- An increase in the Brinkman number leads to a decrease in the Bejan number.

Open Access This is an open access article distributed under the terms of the Creative Commons Attribution License (http://creativecommons.org/licenses/by/4.0), which permits unrestricted use, distribution, and reproduction in any medium, provided the original work is properly cited.

\section{References}

1. M. Bahiraei, M. Jamshidmofid, S. Heshmatian, Adv. Powder Technol. 28, 2380 (2017).

2. S. Heshmatian, M. Bahiraei, Chem. Eng. Sci. 172, 52 (2017).

3. M.W.A. Khan, M.I. Khan, T. Hayat, A. Alsaedi, Physica B 534, 113 (2018).

4. T. Hayat, M.I. Khan, S. Qayyum, A. Alsaedi, M.I. Khan, Phys. Lett. A 382, 749 (2018).

5. M. Bahiraei, N. Mazaheri, A. Bakhti, J. Taiwan Inst. Chem. Eng. 88, 25 (2018).

6. S.E. Ahmed, M.A. Mansour, A. Mahdy, S.S. Mohamed, Eng. Sci. Technol. 20, 1553 (2017).

7. M.R. Sohel, R. Saidur, N.H. Hassan, M.M. Elias, S.S. Khaleduzzaman, I.M. Mahbubul, Int. Commun. Heat Mass Transfer 46, 85 (2013).

8. T. Hayat, M.I. Khan, S. Qayyum, A. Alsaedi, Colloids Surf. A 539, 335 (2018).

9. M. Govindaraju, N.V. Ganesh, B. Ganga, A.K.A. Hakeem, J. Egypt Math. Soc. 23, 429 (2015).

10. S. Qayyum, T. Hayat, M.I. Khan, M.I. Khan, A. Alsaedi, J. Mol. Liq. 262, 261 (2018).

11. G. Nagaraju, J. Srinivas, J.V.R. Murthy, A.M. Rashad, Heat Transf. Asian Res. 46, 316 (2017).

12. M.M. Rashidi, M. Ali, N. Freidoonimehr, F. Nazari, Energy 55, 497 (2013).

13. O. Mahian, S. Mahmud, S.Z. Heris, Energy 44, 438 (2012).

14. N.S. Gibanov, M.A. Sheremet, H.F. Oztop, K.A. Salem, J. Magn. \& Magn. Mater. 452, 193 (2018).

15. M.I. Khan, S. Ullah, T. Hayat, M.I. Khan, A. Alsaedi, J. Mol. Liq. 260, 279 (2018).

16. T. Hayat, M.I. Khan, M. Farooq, A. Alsaedi, M. Waqas, T. Yasmeen, Int. J. Heat Mass Transfer 99, 702 (2016).

17. T. Hayat, M.I. Khan, M. Farooq, T. Yasmeen, A. Alsaedi, J. Mol. Liq. 220, 49 (2016).

18. A. Zeeshan, N. Shehzad, R. Ellahi, Results Phys. 8, 502 (2018).

19. A. Hamid, Hashim, M. Khan, J. Mol. Liq. 262, 435 (2018).

20. M.I. Khan, T. Hayat, M.I. Khan, A. Alsaedi, Int. Commun. Heat Mass Transfer 91, 216 (2018).

21. F.J.R. Hernández, A.I.G. Merino, R.D. García, N.M.P. Flor, Powder Technol. 308, 318 (2017).

22. R.V.M.S.S.K. Kumar, G.V. Kumar, C.S.K. Raju, S.A. Shehzad, S.V.K. Varma, J. Phys. Commun. 2, 035004 (2018).

23. F.G. Awad, S. Motsa, M. Khumalo, PLoS ONE 9, e107622 (2014).

24. D. Lu, M. Ramzan, S. Ahmad, J.D. Chung, U. Farooq, Phys. Fluids 29, 123103 (2017).

25. M. Ramzan, N. Ullah, J.D. Chung, D. Lu, U. Farooq, Sci. Rep. 7, 12901 (2017).

26. M.F. Javed, M.I. Khan, N.B. Khan, R. Muhammad, M.U. Rehmand, S.W. Khan, T.A. Khan, Results Phys. 9, 1250 (2018).

27. N.B. Khan, Z. Ibrahim, L.T.T. Nguyen, M.F. Javed, M. Jameel, PLoS ONE 12, e0185832 (2017).

28. N.B. Khan, Z. Ibrahim, M.I. Khan, T. Hayat, M.F. Javed, Int. J. Heat Mass Transfer. 121, 309 (2018).

29. N.B. Khan, Z. Ibrahim, A.B.B.M. Badry, M. Jameel, M.F. Javed, Proc. Inst. Mech. Eng. Part M: J. Eng. Marit. Environ. (2018) https://doi.org/10.1177/1475090217751326.

30. N.B. Khan, Z. Ibrahim, Proc. Inst. Mech. Eng. Part M: J. Eng. Marit. Environ. (2018) https://doi.org/10.1177/ 1475090217751992.

31. M.I. Khan, M. Waqas, T. Hayat, A. Alsaedi, J. Colloid Interface Sci. 498, 85 (2017).

32. M.W.A. Khan, M.I. Khan, T. Hayat, A. Alsaedi, Physica B 534, 113 (2018).

33. J. Liu, B. Wang, Appl. Numer. Math. 128, 84 (2018).

34. W. Jia, X. He, L. Guo, Appl. Math. Mod. 45, 865 (2017).

35. T. Hayat, M.I. Khan, M. Imtiaz, A. Alsaedi, J. Therm. Sci. Eng. Appl. 10, 011002 (2018).

36. T. Hayat, M.I. Khan, A. Alsaedi, M.I. Khan, Int. Commun. Heat Mass Transfer 89, 190 (2017).

37. M.I. Khan, T. Hayat, M. Waqas, A. Alsaedi, J. Mol. Liq. 230, 143 (2017).

38. T. Hayat, S. Salman, M.I. Khan, A. Alsaedi, Results Phys. 8, 34 (2018).

39. M.I. Khan, M. Waqas, T. Hayat, A. Alsaedi, M.I. Khan, Eur. Phys. J. Plus 132, 489 (2017).

40. T. Hayat, A. Naseem, M.I. Khan, M. Farooq, A. Alsaedi, Phys. Chem. Liq. 56, 189 (2018).

41. M.I. Khan, M. Waqas, T. Hayat, A. Alsaedi, Results Phys. 7, 4183 (2017).

42. T. Hayat, M.I. Khan, M. Farooq, A. Alsaedi, M.I. Khan, Int. J. Heat Mass Transfer 106, 289 (2017).

43. A. Alsaedi, M.I. Khan, T. Hayat, J. Theor. Comput. Chem. 16, 1750064 (2017).

44. T. Hayat, S. Qayyum, M.I. Khan, A. Alsaedi, Chin. J. Phys. 55, 2501 (2017). 
45. T. Hayat, A. Salman, M.I. Khan, A. Alsaedi, Results Phys. 7, 3419 (2017).

46. T. Hayat, M.Z. Kiyani, I. Ahmad, B. Ahmad, Int. J. Mech. Sci. 131, 1016 (2017).

47. M. Waqas, M. Farooq, M.I. Khan, A. Alsaedi, T. Hayat, T. Yasmeen, Int. J. Heat Mass Transfer 102, 766 (2016).

48. S.J. Liao, Homotopic Analysis Method in Nonlinear Differential Equations (Springer, Heidelberg, 2012).

49. M. Waqas, M.I. Khan, T. Hayat, A. Alsaedi, M.I. Khan, Eur. Phys. J. Plus 132, 280 (2017).

50. T. Hayat, M.I. Khan, M. Waqas, A. Alsaedi, Results Phys. 7, 2711 (2017). 